Check for updates

Cite this: Chem. Sci., 2018, 9, 6785

๑ All publication charges for this article have been paid for by the Royal Society of Chemistry

Received 3rd April 2018

Accepted 30th June 2018

DOI: $10.1039 / c 8 s c 01508 b$

rsc.li/chemical-science

\section{Synthesis and structural characterization of inverse-coordination clusters from a two-electron superatomic copper nanocluster $\dagger$}

\author{
Kiran Kumarvarma Chakrahari, ${ }^{a}$ Rhone P. Brocha Silalahi, ${ }^{a}$ Jian-Hong Liao, ${ }^{a}$ \\ Samia Kahlal, ${ }^{b}$ Yu-Chiao Liu, ${ }^{c}$ Jyh-Fu Lee, ${ }^{d}$ Ming-Hsi Chiang, iD c \\ Jean-Yves Saillard (D) *b and C. W. Liu (DD *a
}

We have synthesized and structurally characterized a series of centred cuboctahedral copper clusters, namely $\left[\mathrm{Cu}_{13}\left\{\mathrm{~S}_{2} \mathrm{CNR}_{2}\right\}_{6}\left\{\mathrm{C} \equiv \mathrm{CR}^{\prime}\right\}_{4}\right]\left(\mathrm{PF}_{6}\right)$, 1a-d (where a: $\mathrm{R}={ }^{n} \mathrm{Bu}, \mathrm{R}^{\prime}=\mathrm{CO}_{2} \mathrm{Me} ; \mathrm{b}: \mathrm{R}={ }^{n} \mathrm{Bu}, \mathrm{R}^{\prime}=\mathrm{CO}_{2} \mathrm{Et}$; $\mathrm{c}$ : $\left.\mathrm{R}={ }^{\mathrm{i}} \mathrm{Pr}, \mathrm{R}^{\prime}=\mathrm{CO}_{2} \mathrm{Et} ; \mathrm{d}: \mathrm{R}={ }^{n} \mathrm{Pr}, \mathrm{R}^{\prime}=3,5-\left(\mathrm{CF}_{3}\right)_{2} \mathrm{C}_{6} \mathrm{H}_{3}\right) ;\left[\mathrm{Cu}_{12}\left(\mu_{12}-\mathrm{S}\right)\left\{\mathrm{S}_{2} \mathrm{CNR}_{2}\right\}_{6}\left\{\mathrm{C} \equiv \mathrm{CR}^{\prime}\right\}_{4}\right], 2 \mathrm{a}-\mathrm{C} ;\left[\mathrm{Cu}_{12}\left(\mu_{12}{ }^{-}\right.\right.$ $\left.\mathrm{Cl})\left\{\mathrm{S}_{2} \mathrm{CNR}_{2}\right\}_{6}\left\{\mathrm{C} \equiv \mathrm{CR}^{\prime}\right\}_{4}\right]\left(\mathrm{PF}_{6}\right), 3 \mathrm{a}-\mathrm{e}\left(\right.$ where e: $\left.\mathrm{R}={ }^{n} \mathrm{Bu}, \mathrm{R}^{\prime}=\mathrm{Ph}\right) ;\left[\mathrm{Cu}_{12}\left(\mu_{12}-\mathrm{Br}\right)\left\{\mathrm{S}_{2} \mathrm{CN}^{n} \mathrm{Bu}_{2}\right\}_{6}\{\mathrm{C} \equiv \mathrm{CPh}\}_{4}\right]\left(\mathrm{PF}_{6}\right)$, $4 \mathrm{e}$; and $\left[\mathrm{Cu}_{12}\left(\mu_{12}-\mathrm{Cl}\right)\left(\mu_{3}-\mathrm{Cl}\right)\left\{\mathrm{S}_{2} \mathrm{CN}^{n} \mathrm{Bu}_{2}\right\}_{6}\left\{\mathrm{C} \equiv \mathrm{CCO}_{2} \mathrm{Me}\right\}_{3}\right]^{+} 5 \mathrm{a}$. Cluster $1 \mathrm{a}$ is the first structurally characterized copper cluster having a $\mathrm{Cu}_{13}$ centered cuboctahedral arrangement, a miniature of the bulk copper $f c c$ structure. Furthermore, the partial $\mathrm{Cu}(0)$ character in the 2-electron superatoms 1 was confirmed by XANES. Inverse coordination clusters 2-5 are the first examples of copper clusters containing main group elements $(\mathrm{Cl}, \mathrm{Br}, \mathrm{S})$ with a hyper-coordination number, twelve. A combined theoretical and experimental study was performed, which shows that the central copper (formally $\mathrm{Cu}^{1-}$ ) in nanoclusters 1 can be replaced by chalcogen/halogen atoms, resulting in the formation of clusters 25 which show enhanced luminescence properties and increase in the ionic component of the hostguest interaction as $\mathrm{Br} \approx \mathrm{Cl}>\mathrm{S}>\mathrm{Cu}$, which is consistent with the $\mathrm{Cu}-\mathrm{X}$ Wiberg indices. The new compounds have been characterized by ESI-MS, ${ }^{1} \mathrm{H},{ }^{13} \mathrm{C} N M R, I R, U V$-visible, emission spectroscopy, and the structures $2 a-b, 3 d-e, 4 e$ and $5 a$ were established by $X$-ray diffraction analysis.

\section{Introduction}

The concept of inverse coordination, as recently defined by Haiduc, ${ }^{1}$ applies to metal complexes in which the arrangement of acceptor and donor sites is opposite to that occurring in Werner-type coordination complexes. Inverse coordination complexes are formed around a non-metal species as the central atom (ion) surrounded by a number of metal atoms (ions) connected or not by internal bridging (intramolecular) linkers. Thus, discarding the nature of metal-metal interactions (if any), inverse coordination complexes can be simply viewed as transition-metal clusters (with or without metal-metal bonding) encapsulating a main-group anion.

${ }^{a}$ Department of Chemistry, National Dong Hwa University, No. 1, Sec. 2, Da Hsueh Rd. Shoufeng, Hualien 97401, Taiwan, Republic of China.E-mail: chenwei@mail.ndhu. edu.tw

${ }^{b}$ Univ Rennes, CNRS, ISCR-UMR 6226, F-35000 Rennes, France

'Institute of Chemistry, Academia Sinica, Taipei 11528, Taiwan, Republic of China ${ }^{d}$ National Synchrotron Radiation Research Center, Hsinchu 30076, Taiwan

$\dagger$ Electronic supplementary information (ESI) available. CCDC 1501795, 1815418, 1815419, 1815421-1815424. For ESI and crystallographic data in CIF or other electronic format see DOI: $10.1039 / \mathrm{c} 8 \mathrm{sc} 01508 \mathrm{~b}$
In recent years, our group has developed the chemistry of anion-encapsulated $\mathrm{Cu}^{\mathrm{I}}$ and $\mathrm{Ag}^{\mathrm{I}}$ clusters bridged by dichalcogenolate ligands (dithiocarbamates and dichalcogenophosph(in)ates). ${ }^{2}$ Various high-coordination numbers have been observed and rationalized for anions located at the centre of such $\mathrm{d}^{10}$-metal clusters. ${ }^{3}$ For instance, cubic metal clusters containing an octa-coordinated encapsulated anion are known (Chart 1, left side). ${ }^{4}$ Nona-coordination of a halide or a chalcogenide, where the encapsulated anion lies at the center of an $\mathbf{M}_{11}$ pentacapped trigonal prism (Chart 1, middle), has also been shown to exist., ${ }^{4,5}$ Later, we reported the first example of a dodeca-coordinated iodide lying at the center of an $\mathrm{Ag}_{12}$

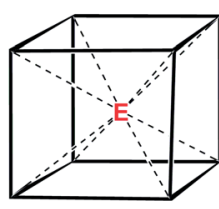

$$
\begin{gathered}
\mathrm{Cu}_{8}^{\prime}\left(\mu_{8}-\mathrm{E}\right) \\
\mathrm{E}=\mathrm{F}^{-}, \mathrm{Cl}^{-}, \mathrm{Br}, \mathrm{S}^{2-}, \mathrm{Se}^{2-}
\end{gathered}
$$

Chart 1 Geometries anions.

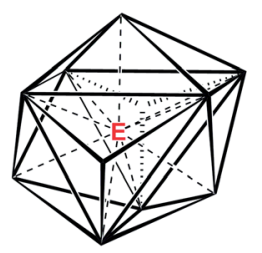

$$
\mathrm{Cu}_{11}^{\prime}\left(\mu_{9}-\mathrm{E}\right)
$$$$
\mathrm{E}=\mathrm{S}^{2-}, \mathrm{Se}^{2-}, \mathrm{I}^{-}, \mathrm{Br}^{-}
$$

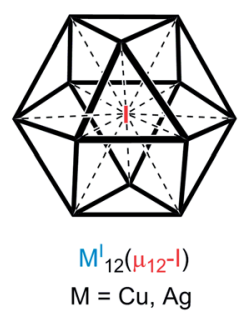


cuboctahedron (Chart 1, right side). ${ }^{4}$ Lang and coworkers reported a cluster having a similar coordination environment for iodide in a cuboctahedral copper core. ${ }^{4 h}$ It is worth noting that in the examples illustrated in Chart 1, no formal covalent bonding exists between the $\mathrm{d}^{10}$ metal centers, but only some metallophilic interactions. ${ }^{6}$

Understanding the mechanisms of nanocluster (NC) formation and reactivity is an important step toward the tailoring of new functional materials. ${ }^{1}$ A substitution reaction is a typical chemical reaction where an atom or a functional group of a molecule is replaced by another atom or functional group. ${ }^{7}$

Compared to substitution reactions on a terminal ligand, substituting an inversely coordinated anion is much more difficult to perform due to the relatively high activation energy associated with this process. ${ }^{8}$ As far as we know, organometallic complexes with a main-group element in a very high coordination number have never been synthesized via the substitution reaction.

Recently, we reported the synthesis and characterization of a series of group 11 cuboctahedral metal NCs of the general formula $\left[\mathrm{Cu}_{12}\left(\mu_{12}-\mathrm{M}\right)\left(\mathrm{S}_{2} \mathrm{CNR}_{2}\right)_{6}\left(\mathrm{C} \equiv \mathrm{CR}^{\prime}\right)_{4}\right]^{+}(\mathrm{M}=\mathrm{Cu}, \mathrm{Ag}, \mathrm{Au}){ }^{9 a}$ In a first approximation, the bonding within these 2-electron superatoms can be described as resulting from the interaction of an encapsulated and formally $\mathbf{M}^{-}$anion with a cuboctahedral cage composed of twelve $\mathrm{Cu}^{\mathrm{I}}$ ions. One fascinating query is whether it should be possible to substitute the encapsulated closed-shell $\mathrm{M}^{-}$anion by a closed-shell main-group anion, and further on, to replace this encapsulated main-group element by another one, the corresponding substitution reactions occurring without cluster disintegration.

Herein, we report the detailed synthesis and characterizations of chalcogen- and halogen-centred copper cuboctahedra. The compounds exhibit three distinct features: (1) the $\mathrm{Cu}_{12}$ framework stabilized by both dithiocarbamate (dtc) and acetylide ligands is unprecedented; (2) the reported $\mu_{12}$ $S$ species are the very first compounds exhibiting a twelvecoordinated chalcogen encapsulated in a copper cluster; (3) the reported $\mu_{12}-\mathrm{Cl}$ species constitute the only third example of a twelve-coordinated halogen in coordination chemistry.

\section{Results and discussion}

\section{Synthesis and characterization}

Previously we have demonstrated that the hydrides present in the copper(I) cluster $\left[\mathrm{Cu}_{28} \mathrm{H}_{15}(\mathrm{dtc})_{12}\right]^{+}$(dtc $=$dibutyldithiocarbamate $=\mathrm{S}_{2} \mathrm{CN}^{n} \mathrm{Bu}_{2}$ ) react with the acidic protons of terminal alkynes to liberate molecular hydrogen, which subsequently reduces the excess of alkynes to alkenes, as well as parts of $\mathrm{Cu}^{\mathrm{I}}$ to $\mathrm{Cu}^{0} .^{9 \boldsymbol{b}}$ The generation of alkynyl ligands in the reaction medium leads eventually to the formation of a brand-new $\mathrm{NC}$ formulated as $\left[\mathrm{Cu}_{13}(\mathrm{dtc})_{6}(\text { alkynyl })_{4}\right]^{+}(\mathbf{1})$, which has a centered cuboctahedral $\left[\mathrm{Cu}_{13}\right]^{11+}$ core possessing two $4 \mathrm{~s}$ cluster electrons $\left(1 \mathrm{~S}^{2}\right.$ closed-shell configuration within the spherical jellium or superatom paradigm $\left.{ }^{\mathbf{1 0}}\right)$. In a typical experiment, to a THF suspension of $\left[\mathrm{Cu}_{28} \mathrm{H}_{15}\left(\mathrm{~S}_{2} \mathrm{CNR}_{2}\right)_{12}\right]^{+}$, a ten-fold excess of terminal alkyne was added and the reaction mixture was stirred at $30^{\circ} \mathrm{C}$ for 24 hours. The solution undergoes a color change from orange to deep red, resulting in the deposition of a dark green solid. Workup of this mixture leads to the isolation of $\left[\mathrm{Cu}_{13}\left\{\mathrm{~S}_{2} \mathrm{CNR}_{2}\right\}_{6}\left\{\mathrm{C} \equiv \mathrm{CR}^{\prime}\right\}_{4}\right]\left(\mathrm{PF}_{6}\right)(\mathbf{1})$ as a dark red solid in $40-$ $70 \%$ yield ( $1 \mathrm{a}(70 \%): \mathrm{R}={ }^{n} \mathrm{Bu}, \mathrm{R}^{\prime}=\mathrm{CO}_{2} \mathrm{Me} ; \mathbf{1 b}(42 \%): \mathrm{R}={ }^{n} \mathrm{Bu}, \mathrm{R}^{\prime}$ $=\mathrm{CO}_{2} \mathrm{Et} ; 1 \mathrm{c}(65 \%): \mathrm{R}={ }^{\mathrm{i}} \mathrm{Pr}, \mathrm{R}^{\prime}=\mathrm{CO}_{2} \mathrm{Et} ; \mathbf{1 d}(55 \%): \mathrm{R}={ }^{n} \mathrm{Pr}, \mathrm{R}^{\prime}=$ $\left.3,5-\left(\mathrm{CF}_{3}\right)_{2} \mathrm{C}_{6} \mathrm{H}_{3}\right)$. In all the cases $\left[\mathrm{Cu}_{8} \mathrm{H}\left(\mathrm{S}_{2} \mathrm{CNR}_{2}\right)_{6}\right]^{+}$and the corresponding alkene (methyl acrylate for $\mathbf{a}$, ethyl acrylate for $\mathbf{b}, \mathbf{c}$, and 1,3-bis(trifluoromethyl)-5-vinylbenzene for d) have been isolated as byproducts. The hydrogen gas released from the reaction of the terminal alkyne's acidic hydrogen with the hydrides of $\left[\mathrm{Cu}_{28} \mathrm{H}_{15}\left(\mathrm{~S}_{2} \mathrm{CN}^{n} \mathrm{R}_{2}\right)_{12}\right]^{+}$is assumed to be the reductant for the partial conversion of the alkyne to an alkene.

The positive-ion ESI mass spectrum of $\mathbf{1 b}-\mathbf{d}$ clearly displays a prominent band for the molecular ion $\left[\mathbf{1 b}-\mathrm{PF}_{6}\right]^{+}$at $\mathrm{m} / z 2438.6$ (calcd 2438.7), [1c-PF $]^{+}$at $m / z 2270.3$ (calcd 2270.5), $[\mathbf{1 d - P F}]^{+}$at $\mathrm{m} / \mathrm{z} 2830.3$ (calcd 2830.4) and their simulated isotopic patterns match well with the experimental observations (Fig. 1a, S1 and $\mathrm{S} 2 \dagger)$. As said above, with two $4 \mathrm{~s}(\mathrm{Cu})$ electrons delocalized on its 13-atom metal core, the cluster cation 1 is a mixed-valent species, more precisely 2-electron superatoms. ${ }^{\mathbf{1 0}}$ Notably, only a few 2-electron copper NCs are known: $\left[\mathrm{Cu}_{25} \mathrm{H}_{22}\left(\mathrm{PPh}_{3}\right)_{12}\right]^{+}$, $\left[\mathrm{Cu}_{29} \mathrm{H}_{22} \mathrm{Cl}_{4}\left(\mathrm{Ph}_{2} \mathrm{Phen}\right)_{12}\right]^{+}$, and $\left[\mathrm{Cu}_{20}(\mathrm{CCPh})_{12}(\mathrm{OAc})_{6}\right],{ }^{11-13}$ and none of them has a cuboctahedral metal core. a)

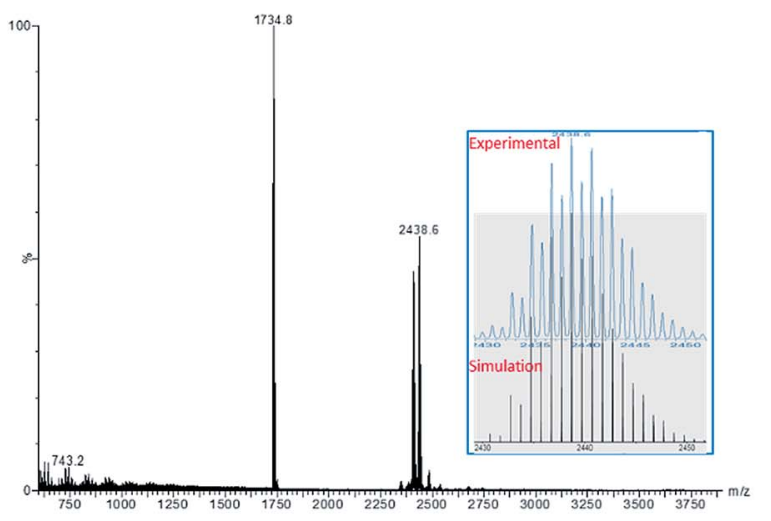

b)

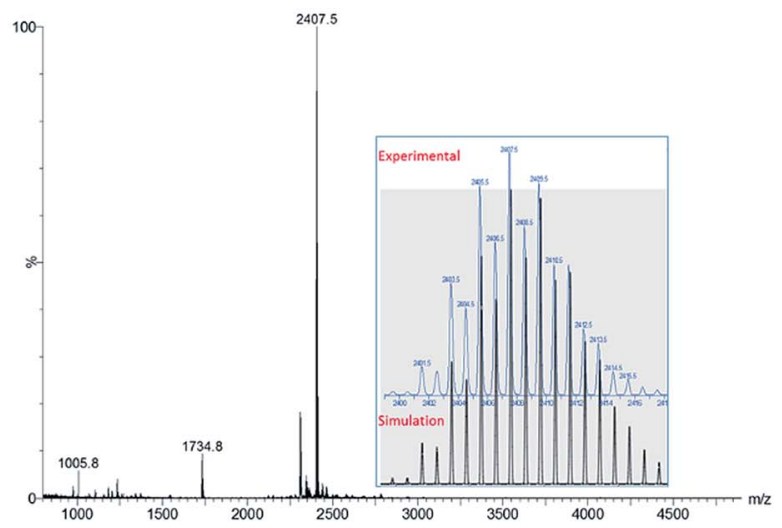

Fig. 1 Positive mode ESI-MS of $1 \mathrm{~b}(\mathrm{a})$ and $2 \mathrm{~b}(\mathrm{~b})$. Insets: experimental and simulated mass spectra. 
${ }^{1} \mathrm{H}$ and ${ }^{13} \mathrm{C}$ NMR spectra of $\mathbf{1 a}-\mathbf{d}$ show one set of signals, consistently with $T_{\mathrm{d}}$ symmetry in solution (see below). Their FTIR spectra show that the alkynyl $\nu(\mathrm{C} \equiv \mathrm{C})$ stretching frequencies are lower than in the corresponding alkyne $\left(\nu\left(\mathrm{HC} \equiv \mathrm{CR}^{\prime}\right)=\right.$ $2129 \mathrm{~cm}^{-1}$ ). 1a shows a band at $2017.5 \mathrm{~cm}^{-1}$. This value is slightly higher than in $\left[\mathrm{Cu}_{3}(\mu-\mathrm{dppm})_{3}\left(\mu_{3}-\eta^{1}-\mathrm{C} \equiv \mathrm{CCOO}\right)\left(\mu_{3^{-}}\right.\right.$ $\left.\left.\mathrm{OCH}_{3}\right)\right]\left(1976 \mathrm{~cm}^{-1}\right) \cdot{ }^{14}$ The effect of $\mathrm{Cu}$ oxidation state(s) and cluster nuclearity is evident in the $\mathrm{Cu}$ K-edge X-ray absorption near-edge spectra (XANES) of 1a-d (Fig. 2). At $\sim 8979.8 \mathrm{eV}$, the edge position of 1a-d is very similar to that of copper NCs, $\left[\mathrm{Cu}_{29} \mathrm{Cl}_{4} \mathrm{H}_{22}\left(\mathrm{Ph}_{2} \mathrm{Phen}\right)_{12}\right](\mathrm{Cl})$ and $\quad\left[\mathrm{Cu}_{25} \mathrm{H}_{22}\left(\mathrm{PPh}_{3}\right)_{12}\right](\mathrm{Cl})$ reported by Hayton ${ }^{\mathbf{1 1 , 1 2}}$ and resides between values measured for $\mathrm{Cu}^{0}$ in the bulk foil $(8979.0 \mathrm{eV})$ and $\mathrm{Cu}^{\mathrm{I}}$ in clusters such as $\left[\mathrm{Cu}_{28}(\mathrm{H})_{15}\left(\mathrm{~S}_{2} \mathrm{CN}^{n} \mathrm{Bu}_{2}\right)_{12}\right]\left(\mathrm{PF}_{6}\right) \quad(8980.1 \mathrm{eV})$ and $\left[\mathrm{Cu}_{8}(\mathrm{H})-\right.$ $\left.\left(\mathrm{S}_{2} \mathrm{CN}^{n} \mathrm{Bu}_{2}\right)_{6}\right]\left(\mathrm{PF}_{6}\right)(8980.3 \mathrm{eV})$. This is consistent with an average $\mathrm{Cu}$ oxidation state between 0 and +1 for $\mathbf{1 a - d}$ (Table 1 ).

Compound $\mathbf{2 a}$ has been synthesized by reacting $1 \mathbf{a}$ with a two-fold excess of $\mathrm{K}\left[\mathrm{S}_{2} \mathrm{CN}^{n} \mathrm{Bu}_{2}\right]$ and the reaction mixture was stirred for 24 hours at $0{ }^{\circ} \mathrm{C}$ (Scheme 1). The solution undergoes a color change from deep red to orange. Immediate workup of this mixture leads to the isolation of $\left[\mathrm{SCu}_{12}\left(\mathrm{~S}_{2} \mathrm{CN}^{n} \mathrm{Bu}_{2}\right)_{6}\right.$ $\left.(\mathrm{C} \equiv \mathrm{CCOOMe})_{4}\right]$ (2a) as a dark orange solid in $22 \%$ yield. Clusters $\mathbf{2 b}$ and $\mathbf{2 c}$ were isolated by following a similar synthetic procedure. The positive-ion ESI mass spectrum clearly displays

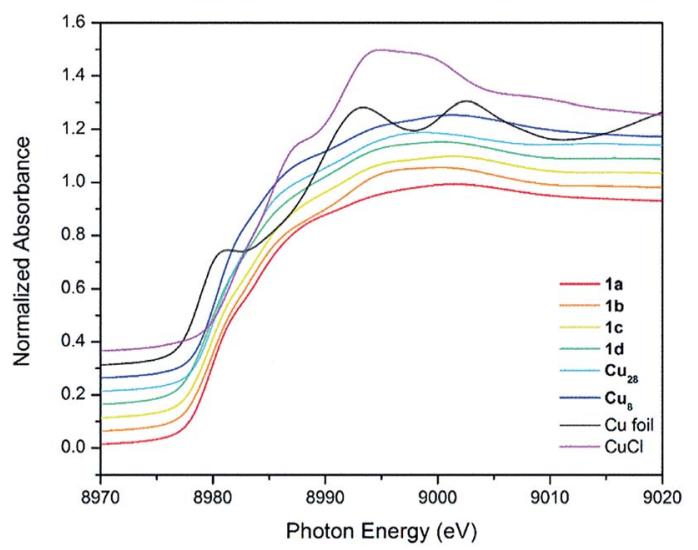

Fig. 2 Comparison of $\mathrm{Cu} \mathrm{K}$-edge XANES profiles for $\mathrm{Cu}$ foil, $\mathrm{CuCl}$, copper(I) hydrides and NCs 1a-d.

Table $1 \mathrm{Cu}$ K-edge energies for selected $\mathrm{Cu}^{0}$ and $\mathrm{Cu}^{\prime}$ species

\begin{tabular}{|c|}
\hline Material \\
\hline $\begin{array}{l}\mathrm{Cu} \text { foil } \\
{\left[\mathrm{Cu}_{25} \mathrm{H}_{22}\left(\mathrm{PPh}_{3}\right)_{12}\right] \mathrm{Cl}^{11}} \\
{\left[\mathrm{Cu}_{29} \mathrm{Cl}_{4} \mathrm{H}_{22}\left(\mathrm{Ph}_{2} \mathrm{Phen}_{12}\right] \mathrm{Cl}^{12}\right.} \\
{\left[\mathrm{Cu}_{13}\left(\mathrm{~S}_{2} \mathrm{CN}^{n} \mathrm{Bu}_{2}\right)_{6}\left(\mathrm{C}_{3} \mathrm{O}_{2} \mathrm{Me}_{4}\right] \mathrm{PF}_{6}(\mathbf{1 a})\right.} \\
{\left[\mathrm{Cu}_{13}\left(\mathrm{~S}_{2} \mathrm{CN}^{n} \mathrm{Bu}_{2}\right)_{6}\left(\mathrm{C}_{3} \mathrm{O}_{2} \mathrm{Et}_{4}\right] \mathrm{PF}_{6}(\mathbf{1 b})\right.} \\
{\left[\mathrm{Cu}_{13}\left(\mathrm{~S}_{2} \mathrm{CN}^{1} \mathrm{Pr}_{2}\right)_{6}\left(\mathrm{C}_{3} \mathrm{O}_{2} \mathrm{Et}_{4}\right)_{4}\right] \mathrm{PF}_{6}(\mathbf{1 c})} \\
{\left[\mathrm{Cu}_{13}\left(\mathrm{~S}_{2} \mathrm{CN}^{n} \mathrm{Pr}_{2}\right)_{6}\left\{\left(\mathrm{CF}_{3}\right)_{2} \mathrm{C}_{6} \mathrm{H}_{3}\right\}_{4}\right] \mathrm{PF}_{6}(\mathbf{1 d})} \\
\mathrm{Cu}_{2} \mathrm{O} \\
{\left[\mathrm{Cu}_{28}(\mathrm{H})_{15}\left(\mathrm{~S}_{2} \mathrm{CN}^{n} \mathrm{Bu}_{2}\right)_{12}\right] \mathrm{PF}_{6}} \\
{\left[\mathrm{Cu}_{8}(\mathrm{H})\left(\mathrm{S}_{2} \mathrm{CN}^{n} \mathrm{Bu}_{2}\right)_{6}\right] \mathrm{PF}_{6}} \\
{\left[\mathrm{Cu}\left(\mathrm{CH}_{3} \mathrm{CN}\right)_{4}\right] \mathrm{PF}_{6}} \\
\mathrm{CuCl}\end{array}$ \\
\hline
\end{tabular}
Edge (eV)

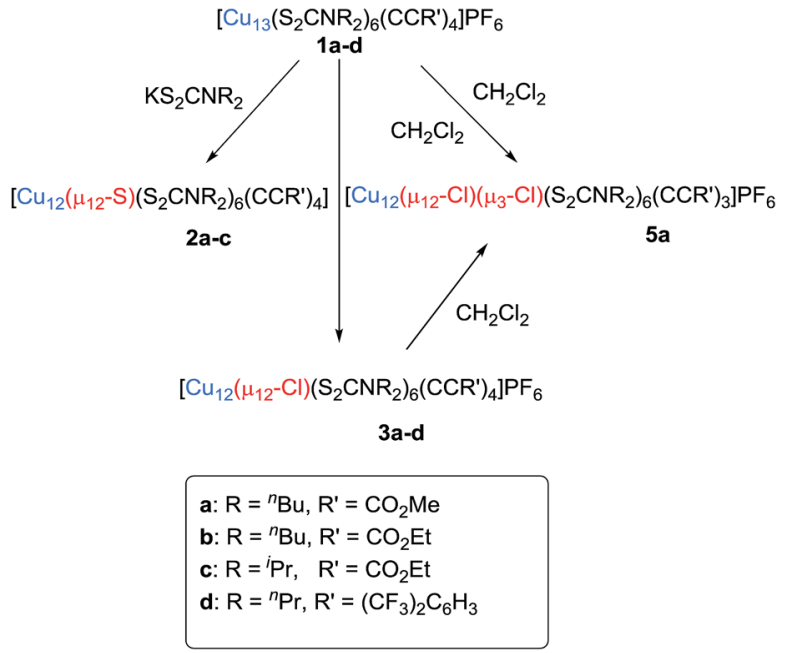

Scheme 1 Substitution reactions for the synthesis of compounds 2, 3, and 5 from 1 .

a prominent band for the molecular ion $[\mathbf{2 a}]^{+}$at $\mathrm{m} / \mathrm{z} 2351.6$ (calcd 2351.7), [2b] $]^{+}$at $\mathrm{m} / \mathrm{z} 2407.5$ (calcd 2407.7), [2c $]^{+}$at $\mathrm{m} / \mathrm{z}$ 2239.0 (calcd 2237.5), and their simulated isotopic patterns match well with the experimental observation (Fig. 1b, S3 and $\mathrm{S} 4 \dagger)$. The presence of a sulfide atom in $\mathbf{2 a - c}$ clearly originates from the dtc ligand. Indeed, the formation of $\mathrm{S}^{2-}$ from the sulfur-carbon bond cleavage in dtc ligands has been well documented. ${ }^{15}$

Compounds 3a-d were isolated as yellow solids in 11-30\% yield from the reaction of $\mathbf{1 a - d}$ with dichloromethane for three days under ambient conditions. This reaction also produced $\left[\mathrm{Cu}_{11} \mathrm{Cl}_{4}\left(\mathrm{~S}_{2} \mathrm{CNR}_{2}\right)_{6}\right]^{+}$and a series of chloride-centred $\mathrm{Cu}_{12}$ cuboctahedral clusters with a different number of acetylide ligands $\left[\mathrm{Cu}_{12}\left(\mu_{12}-\mathrm{Cl}\right)\left(\mu_{3}-\mathrm{Cl}\right)_{n}\left\{\mathrm{~S}_{2} \mathrm{CNR}_{2}\right\}_{6}\left\{\mathrm{C} \equiv \mathrm{CR}^{\prime}\right\}_{4-n}\right]\left(\mathrm{PF}_{6}\right)(n=$ 1-3), whose compositions were confirmed by ESI mass spectroscopy (Fig. S6 and S7†). This result suggests that three among the four acetylides of compound 3 can be replaced by halides. The geometric structure of $\left[\mathrm{Cu}_{11} \mathrm{Cl}_{4}\left(\mathrm{~S}_{2} \mathrm{CNR}_{2}\right)_{6}\right]^{+}$ is presumably similar to that of our previously reported $\left[\mathrm{Cu}_{11}\left(\mu_{9}-\mathrm{Br}\right)\left(\mu_{3}-\mathrm{Br}\right)_{3}\left\{\mathrm{~S}_{2} \mathrm{P}\left(\mathrm{O}^{\mathrm{i}} \mathrm{Pr}\right)_{2}\right\}_{6}\right]^{+} .^{5} \quad$ Separation of these compounds by column chromatography was difficult. However, we were lucky to grow single crystals of $\mathbf{5 a}\left[\mathrm{Cu}_{12}\left(\mu_{12}-\mathrm{Cl}\right)\left(\mu_{3}-\mathrm{Cl}\right)\right.$ $\left.\left\{\mathrm{S}_{2} \mathrm{CNR}_{2}\right\}_{6}\left\{\mathrm{C} \equiv \mathrm{CO}_{2} \mathrm{Me}\right\}_{3}\right]^{+}$, which was characterized by X-ray crystallography (vide infra).

We have increased the yields in the production of compounds 3 by designing an alternative synthetic procedure. The direct synthesis involved the reaction of a terminal alkyne with a THF suspension of $\mathrm{Cu}^{\mathrm{I}}$ salts and dtc ligands followed by the addition of few drops of triethylamine (Scheme 2). The reaction mixture was stirred at room temperature for ten minutes followed by the addition of tetrabutylammonium halide. The resulting solution was stirred for 12 hours, leading to the isolation of compounds $3 \mathrm{e}$ and $4 \mathrm{e}$ with $45 \%$ and $52 \%$ yields, respectively. The spectroscopic data of $\mathbf{3 e}$ and $\mathbf{4 e}$ are fully consistent with their X-ray structures described below (Fig. 3). The positive-ion ESI mass spectra clearly display a prominent band for the molecular ion $\left[3 \mathbf{a}-\mathrm{PF}_{6}\right]^{+}$at $\mathrm{m} / \mathrm{z} 2354.8$ (calcd 


$$
12\left[\mathrm{Cu}\left(\mathrm{CH}_{3} \mathrm{CN}\right)_{4}\right] \mathrm{PF}_{6}+6 \mathrm{KS}_{2} \mathrm{CNBu}_{2}+4 \mathrm{HC} \equiv \mathrm{CPh} \frac{\mathrm{Et}_{3} \mathrm{~N}, \mathrm{Bu}_{4} \mathrm{NX}}{\mathrm{THF}}\left[\left(\mu_{12}-\mathrm{X}\right) \mathrm{Cu}_{12}\left(\mathrm{~S}_{2} \mathrm{CN}^{n} \mathrm{Bu}_{2}\right)_{6}\left(\mathrm{C} \equiv \mathrm{CPh}_{4}\right] \mathrm{PF} F_{6} \begin{array}{l}
3 \mathrm{e}: \mathrm{X}=\mathrm{Cl} \\
4 \mathrm{e}: \mathrm{X}=\mathrm{Br}
\end{array}\right.
$$

Scheme 2 An alternative method for the synthesis of $3 e$ and $4 e$.

a)

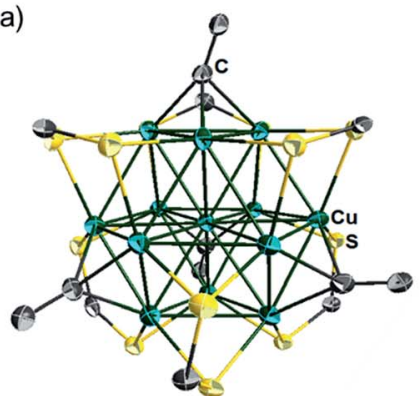

b)

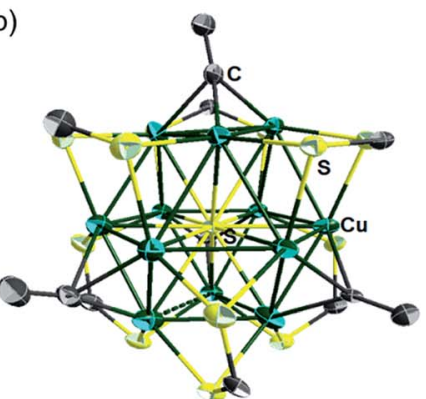

c)

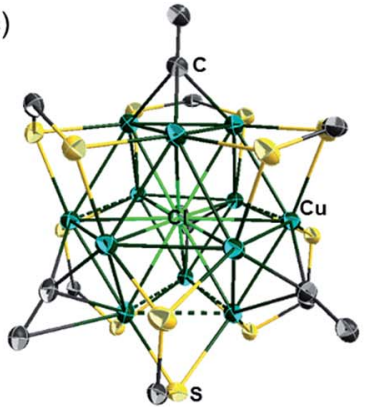

d)

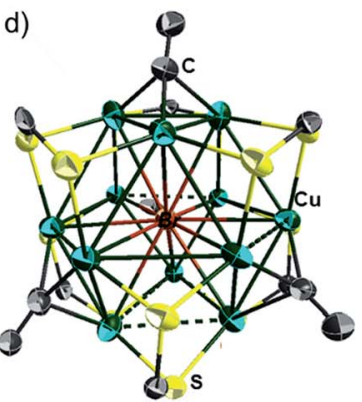

Fig. 3 Single crystal structures of the cluster cation $1 \mathrm{a}$ (a), cluster $2 \mathrm{a}$ (b), cluster cations of $3 \mathrm{e}$ (c) and $4 \mathrm{e}$ (d) with $30 \%$ thermal probability ellipsoids. All N $\mathrm{Nu}_{2}, \mathrm{C}(\mathrm{O}) \mathrm{OMe}(1 \mathrm{a}, 2 \mathrm{a})$ and phenyl $(3 \mathrm{e}, 4 \mathrm{e})$ moieties are omitted for clarity.

2354.7), $\left[3 \mathbf{b}-\mathrm{PF}_{6}\right]^{+}$at $\mathrm{m} / \mathrm{z} 2410.7$ (calcd 2410.7), $\left[3 \mathbf{c}-\mathrm{PF}_{6}\right]^{+}$at $\mathrm{m} / \mathrm{z}$ 2242.5 (calcd 2240.5), [3d-PF $]^{+}$at $m / z 2802.3$ (calcd 2802.5), [3e$\left.\mathrm{PF}_{6}\right]^{+}$at $m / z 2426.4$ (calcd 2426.8), and $\left[4 \mathrm{e}-\mathrm{PF}_{6}\right]^{+}$at $\mathrm{m} / z 2470.5$ (calcd 2470.7), and their simulated isotopic patterns match well with the experimental observation (Fig. 4 and S6-S9†).

FT-IR spectra of $3 \mathbf{e}$ and $4 \mathbf{e}$ show that the $\nu(\mathrm{C} \equiv \mathrm{C})$ stretching frequencies (2014, and $2015 \mathrm{~cm}^{-1}$ respectively) are lower than the values found for the corresponding alkyne $(\nu(\mathrm{HC} \equiv \mathrm{CPh})=$ $2110 \mathrm{~cm}^{-1}$ ).

In solution, ${ }^{1} \mathrm{H}$ NMR spectra for compounds $2 \mathbf{a}, 3 \mathbf{e}$ and $4 \mathrm{e}$ were recorded at variable temperatures $(183,193,243$ and 273 K), which show only one set of ligands (in line with $T_{\mathrm{d}}$ symmetry, Fig. S10 $\dagger$ ). ${ }^{1} \mathrm{H}$ and ${ }^{13} \mathrm{C}$ NMR spectroscopic analyses of 5 show one set of ligands illustrating that the molecule is highly symmetric in solution. This is consistent with the ligand distribution pattern in 1, implying their similarity in structure. Indeed, the ${ }^{1} \mathbf{H}$ chemical shifts of $\mathbf{1 a}$ and $\mathbf{5 a}$ are similar but their integration ratios are different. Clusters 1-4 contain six dtc ligands and four alkynyl groups, whereas the ${ }^{1} \mathrm{H}$ NMR spectrum of 5a shows the integration value of three alkynyl groups for six $n$-butyl dtc ligands. The replacement of one of the alkynyl groups with chloride is further confirmed by the ESI mass spectrum, where 5a shows the molecular ion $[\mathbf{5 a}]^{+}$peak at $\mathrm{m} / \mathrm{z}$ 2308.4 (calcd 2306.6) (Fig. S11†).

\section{Structural analysis}

The single-crystal X-ray structures of $\mathbf{1 a}, \mathbf{2 a}, \mathbf{2 b}, \mathbf{3 d}, \mathbf{3 e}$ and $\mathbf{4 e}$ are given in Fig. 3a, b, S5, S12, $\uparrow 3 \mathrm{c}$ and $\mathrm{d}$ respectively. Corresponding relevant metrical data are given in Table 2. They all clearly show an $\mathrm{X}$-centered $\mathrm{Cu}_{12}$ cuboctahedron $(\mathrm{X}=\mathrm{Cu}(\mathbf{1}), \mathrm{S}$ (2), $\mathrm{Cl}(\mathbf{3 d}, 3 \mathbf{e}), \mathrm{Br}(\mathbf{4 e}))$. The six square faces of the $\mathrm{Cu}_{12}$ cuboctahedron are capped by six dtc ligands, each of them bridging four metal centres in a $\left(\mu_{2}, \mu_{2}\right)$ binding mode. As a)

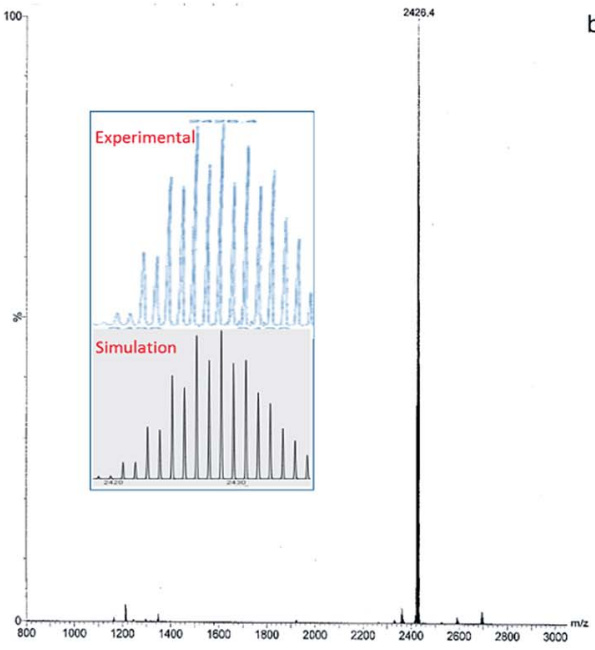

b) 100

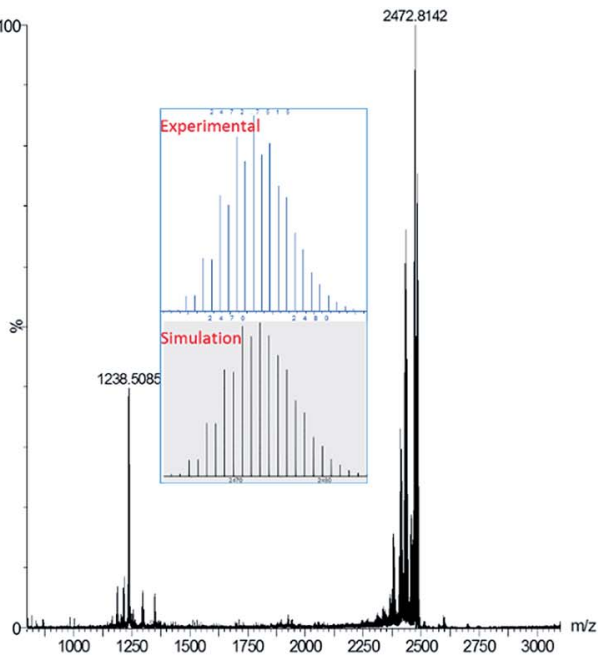

Fig. 4 Positive mode ESI-MS of 3 e (a), 4e (b). The insets show experimental and simulated mass spectra. 
Table 2 Selected bond lengths ( $\AA$ ) for $1 a, 2 a-b, 3 d-e, 4 e$ and $5 a$

\begin{tabular}{|c|c|c|c|c|c|c|}
\hline & $\mathrm{X}_{\text {cent }}$ & $\mathrm{X}_{\text {cent }}-\mathrm{Cu}$ & $\mathrm{Cu}-\mathrm{Cu}$ & $\mathrm{C} \equiv \mathrm{C}$ & $\mathrm{Cu}_{\text {cubo }}-\mathrm{C}$ & $\mathrm{Cu}_{\text {cubo }}-\mathrm{S}$ \\
\hline $1 a^{9}$ & & Avg. 2.636 & Avg. 2.636 & Avg. 1.202 & Avg. 2.035 & Avg. 2.289 \\
\hline & & Avg. 2.706 & Avg. 2.709 & Avg. 1.201 & Avg. 2.094 & Avg. 2.295 \\
\hline \multirow[t]{2}{*}{$2 \mathbf{b}$} & $\mathrm{S}$ & $2.561-2.892$ & $2.549-3.128$ & $1.143-1.200$ & $2.002-2.203$ & $2.264-2.359$ \\
\hline & & Avg. 2.713 & Avg. 2.717 & Avg. 1.178 & Avg. 2.092 & Avg. 2.302 \\
\hline \multirow[t]{2}{*}{$3 \mathbf{e}$} & $\mathrm{Cl}$ & $2.807-3.035$ & $2.527-3.212$ & $1.205-1.257$ & $1.956-2.075$ & $2.243-2.291$ \\
\hline & & Avg. 2.926 & Avg. 2.884 & Avg. 1.225 & Avg. 2.025 & Avg. 2.267 \\
\hline \multirow[t]{2}{*}{$4 e$} & $\mathrm{Br}$ & $2.881-3.072$ & $2.563-3.306$ & $1.165-1.217$ & $1.943-2.100$ & $2.238-2.311$ \\
\hline & & Avg. 2.977 & Avg. 2.975 & Avg 1.190 & Avg. 2.029 & Avg. 2.269 \\
\hline \multirow[t]{2}{*}{$5 a$} & $\mathrm{Cl}$ & $2.635-2.911$ & $2.563-3.245$ & $1.059-1.174$ & $1.985-2.173$ & $2.249-2.316$ \\
\hline & & Avg. 2.778 & Avg. 2.781 & Avg. 1.134 & Avg. 2.084 & Avg. 2.279 \\
\hline
\end{tabular}

a result, the twelve dtc sulfur atoms form a truncated tetrahedral cage. Four among the eight triangular faces of the cuboctahedron are capped by alkynyl groups in a $\mu_{3}-\eta^{1}$ fashion. It follows that each of the twelve outer $\mathrm{Cu}$ atoms is in an approximately planar $\mathrm{CuS}_{2} \mathrm{C}$ coordination mode (not taking into account bonding with $\mathrm{X}$ ). Not considering the substituents on alkynyls, the idealized symmetry of the clusters is $T_{\mathrm{d}}$. The main-group-centered structures (2a, b, 3d, $\mathbf{e}$ and $\mathbf{4 e})$ are however more distorted away from this ideal symmetry than that with $\mathrm{X}$ $=\mathrm{Cu}(\mathbf{1 a})$. This is exemplified by the larger dispersion of the $\mathrm{Cu}-$ $\mathrm{Cu}$ and $\mathrm{X}-\mathrm{Cu}$ distances. All these structures exhibit one rather long $\mathrm{X}-\mathrm{Cu}$ distance (Table 2) but still within bonding contacts (see below). The $\mathrm{Cu}-\left(\mu_{12}-\mathrm{S}\right)$ bond lengths of $2 \mathbf{a}, \mathbf{b}$ are in the range 2.561(3)-2.934(4) $\AA$, i.e. longer but comparable to that of $\mathrm{Cu}-\left(\mu_{9}-\mathrm{S}\right) 2.402-2.870 \AA$ in $\left[\mathrm{Cu}_{11}\left(\mu_{9}-\mathrm{S}\right)\left(\mu_{3}-\mathrm{Br}\right)_{3}\left\{\mathrm{~S}_{2} \mathrm{P}\left(\mathrm{O}^{\mathrm{i}} \mathrm{Pr}\right)_{2}\right\}_{6}\right]^{5 a}$ The average $\mathrm{Cu}-\left(\mu_{12}-\mathrm{Br}\right)$ distance in $4 \mathbf{e}(2.977 \AA)$ is comparable to the $\mathrm{Cu}-\left(\mu_{9}-\mathrm{Br}\right)$ distance $(2.942 \AA)$ observed in $\left[\mathrm{Cu}_{11}\left(\mu_{9}-\mathrm{Br}\right)\left(\mu_{3}\right.\right.$ $\left.\mathrm{Br})_{3}\left\{\mathrm{~S}_{2} \mathrm{P}\left(\mathrm{O}^{\mathrm{i}} \mathrm{Pr}\right)_{2}\right\}_{6}\right]^{+} .^{5}$ The average $\mathrm{Cu}-\left(\mu_{8}-\mathrm{X}\right)$ distance in $\left[\mathrm{Cu}_{8}\left(\mu_{8^{-}}\right.\right.$ $\left.\mathrm{X})\left\{\mathrm{S}_{2} \mathrm{P}\left(\mathrm{O}^{\mathrm{i}} \mathrm{Pr}\right)_{2}\right\}\right]^{+}$is shorter than in $\mathbf{3 d}, \mathbf{e}$ and $\mathbf{4 e}(2.72$ (ref. $4 \mathrm{c})$ and $2.74 \AA$ (ref. $4 \mathrm{~d}$ ) for $\mathrm{Cl}$ and $\mathrm{Br}$, respectively). The average $\mathrm{Cu}-\mathrm{Cu}$ distances in compounds $\mathbf{2} \mathbf{a}-\mathbf{b}, \mathbf{3} \mathbf{3}-\mathbf{e}$ and $\mathbf{4 e}$ are larger than in the $\mathrm{Cu}$-centered cluster $\mathbf{1 a}$, the largest value corresponding to the bromine-centered cluster $4 \mathbf{e}$, presumably owing to the larger size of bromine. In this particular compound, the $\mathrm{Cu}-\mathrm{Cu}$ distance overpasses the sum of the van der Waals radii and it can be anticipated that the entrapment of anions larger than bromide into the $\mathrm{Cu}_{12}^{\mathrm{I}}$ cage would destabilize the structure. For all the structures reported in Table 2, the $\mathrm{Cu}-\mathrm{S}(\mathrm{dtc}) \mathrm{Cu}-\mathrm{C}$ and $\mathrm{C} \equiv \mathrm{C}$ bond distances (Table 2) are in the normal range and vary little across the series. The highest coordination number found in the literature is 8 for chloride and 9 for bromide. ${ }^{4}$ Thus, to the best of our knowledge, compounds $\mathbf{3 d}-\mathbf{e}$ and $4 \mathbf{e}$ are the first isolated examples of $\mu_{12}$-chloride and $\mu_{12}$-bromide encapsulated in molecular compounds. In these clusters, as well as in the copper- and sulfide-centered species, the central atom plays a template role in the formation of this large cluster. This cuboctahedral configuration represents a marked contrast with the centered icosahedral geometry observed in the core unit of $\left[\mathrm{Ag}_{20}\left\{\mathrm{E}_{2} \mathrm{P}\left(\mathrm{O}^{\mathrm{i}} \mathrm{Pr}\right)_{2}\right\}_{12}\right](\mathrm{E}=\mathrm{S}, \mathrm{Se})$ and $\left[\mathrm{Ag}_{21}\left\{\mathrm{~S}_{2} \mathrm{P}\left(\mathrm{O}^{\mathrm{i}} \mathrm{Pr}\right)_{2}\right\}_{12}\right]^{+}{ }^{+16}$ It is worth mentioning that no guest element exists in the dodecahedral structures of $\left[\mathrm{Cu}_{12} \mathrm{~S}_{8}\right]^{4-},\left[\mathrm{Cu}_{12}(\mathrm{NPh})_{8}\right]^{4-},\left[\left({ }^{t} \mathrm{Bu}_{3}-\right.\right.$ $\left.\mathrm{SiP})_{6} \mathrm{Cu}_{12}\right]$, and $\left[\mathrm{Cu}_{12} \mathrm{E}_{6}\left(\mathrm{PR}_{3}\right)_{8}\right](\mathrm{E}=\mathrm{S}, \mathrm{Se}, \mathrm{Te}) .{ }^{17}$ Whereas a couple of examples of $\mathrm{Au}_{12}$ and $\mathrm{Ag}_{12}$ dodecahedra encapsulating a sodium or silver atom, respectively, are known, ${ }^{18}$ compounds 1-5 are the first examples of a copper cuboctahedron encapsulating another atom (except for Lang's compound of ref. $4 \mathrm{~h}$ ). In the case of 1a, the metallic core is, to the best of our knowledge, the first example of a copper-centred $\mathrm{Cu}_{13}$ cuboctahedron, identical to that observed in the $f c c$ structure of bulk copper.

The X-ray structure of 5a (Fig. 5 and Table 2) can be derived from that of 3 by replacing one of the four $\mu_{3}$-alkynyl moieties by an isolobal $\mu_{3}-\mathrm{Cl}$ ligand, which lowers the cluster ideal symmetry from $T_{\mathrm{d}}$ to $C_{3 \mathrm{v}}$. Apart from this substitution, the structure of $\mathbf{5 a}$ is similar to that of clusters $\mathbf{3}$. Not considering bonding with the encapsulated chloride, three among the twelve copper atoms are in the $\mathrm{CuS}_{2} \mathrm{Cl}$ coordination, leaving nine other metals in a $\mathrm{CuS}_{2} \mathrm{C}$ coordination. 5 a exhibits a broad range of $\mathrm{Cu}-\mathrm{Cu}$ distances $(2.563-3.245 \AA)$. The corresponding average value $(2.781 \AA)$ is shorter than that observed in $3 \mathbf{d}(2.844$ $\AA)$. The average $\mathrm{Cu}-\left(\mu_{12}-\mathrm{Cl}\right)$ distance in $\mathbf{5 a}(2.778 \AA)$ is substantially larger than that corresponding to the $\mathrm{Cu}-\left(\mu_{3}-\mathrm{Cl}\right)$ distance (2.321 $\AA$ ). Interestingly, the $\mathrm{C} \equiv \mathrm{C}$ distances of $5 \mathrm{a}$ (avg. $1.134 \AA$ ) are significantly shorter than that of the tetra-alkynyl species reported in Table 2 (avg. 1.19-1.22 ̊).

\section{Optical properties}

It is fascinating that a single atom alteration between clusters 13 can lead to diverse variances in their UV-vis spectra (Fig. 6). The homo-nuclear $\mathrm{Cu}_{13}$ cluster (1a) looks pinkish to the naked eye, whereas the sulfide- (2a) and chloride- (3a) centred clusters appear to be orange. The UV-vis spectrum of 1a shows broad multiband optical absorption (at 337, 513, 540, $571 \mathrm{~nm}$ ) and an intense absorption band at $287 \mathrm{~nm}$, whereas the inverse coordination clusters $2 \mathbf{a}(317,450 \mathrm{~nm})$ and $3 \mathbf{a}(312 \mathrm{~nm})$ show different patterns in their UV-vis spectrum. Substitution of the central metal atom $(\mathrm{Cu})$ in $\mathbf{1}$ with main-group elements like sulfur and halogen increases the intensity of photoemission. At $77 \mathrm{~K}$ clusters $\mathbf{2 a}$ and $\mathbf{3 a}$ exhibit a structureless emission band, centred at 562 and $585 \mathrm{~nm}$, respectively (Fig. S13†). On the other hand, the compound $\mathbf{1}$ is almost non-emissive. 


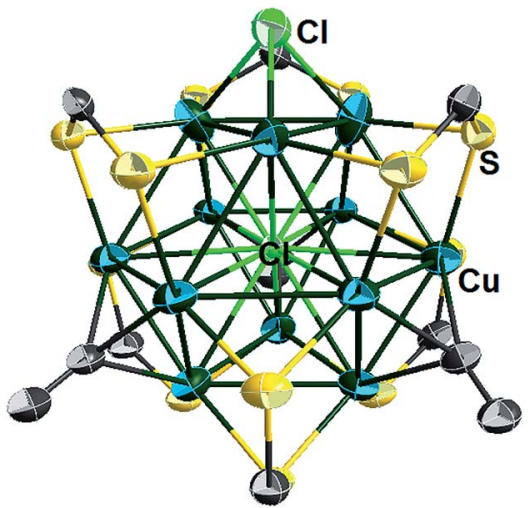

Fig. 5 Single crystal structure of the cluster cation 5 a with $30 \%$ thermal probability ellipsoids. All $\mathrm{N}^{n} \mathrm{Bu}_{2}$ and $\mathrm{C}(\mathrm{O}) \mathrm{OCH}_{3}$ moieties are omitted for clarity.

\section{Theoretical investigations}

In order to shed some light on the bonding and properties of the reported inverse-coordinated clusters, density functional theory (DFT) calculations were performed on various model clusters. The simplest homologs of compounds $\mathbf{1 - 4}$, namely $\mathbf{1}^{\prime}-$ $\mathbf{4}^{\prime}$, were built with $\mathrm{S}_{2} \mathrm{CNR}_{2}=\mathrm{S}_{2} \mathrm{CNH}_{2}$ and $\mathrm{CCR}^{\prime}=\mathrm{CCH}$. Relevant computed data are given in Table 3 . The optimized geometries of $\mathbf{1}^{\prime}-\mathbf{4}^{\prime}$ were all found to be of exact $T_{\mathrm{d}}$ symmetry (no imaginary vibrational frequency). Their metrical parameters are in good agreement with the averaged experimental values of compounds 1-4 (Table 2). Unsurprisingly, the computed natural atomic orbital (NAO) charges are consistent with the formal oxidation state of the encapsulated element $\mathrm{X}$ being $\mathrm{Cu}^{-}, \mathrm{S}^{2-}, \mathrm{Cl}^{-}$and $\mathrm{Br}^{-}$in clusters $\mathbf{1}^{\prime}$ to $\mathbf{4}^{\prime}$, respectively, whereas those of the 12 cuboctahedral metals always indicate the $\mathrm{Cu}^{+}$ state. However, the differences between the computed and formal charges of $\mathrm{X}$ vary with its nature, indicating that the covalent component of the host-guest interaction decreases as $\mathrm{Cu}>\mathrm{S}>\mathrm{Br} \approx \mathrm{Cl}$. The $\mathrm{Cu}-\mathrm{X}$ Wiberg indices (Table 3) are also consistent with this view. Thus $\mathbf{1}^{\prime}(\mathrm{X}=\mathrm{Cu})$ is substantially more covalent than $\mathbf{3}^{\prime}(\mathrm{X}=\mathrm{Cl})$. The simplified interaction diagrams of Fig. 7 illustrate this situation. Considering that each approximately planar tricoordinated $\mathrm{Cu}^{\mathrm{I}}$ cuboctahedral vertex has a $4 \mathrm{p}$ vacant orbital pointing toward the middle of the cage, one is left with 12 vacant combinations $\left(a_{1}+e+t_{1}+2 t_{2}\right)$ for the whole empty cage, of which the lowest ones $\left(a_{1}+t_{2}\right)$ constitute a nice set of accepting orbitals. In the case of $\mathrm{X}=\mathrm{Cu}$, the occupied $4 \mathrm{~s}$ orbital of the encapsulated formally $\mathrm{Cu}^{1-}$ metal and the $\mathrm{a}_{1}$ accepting orbital of the cage interact strongly, because of their proximity in energy. The resulting bonding $\mathrm{a}_{1}$ MO is substantially delocalized on the 13 copper atoms and therefore both $\mathrm{Cu}_{\text {cent }}-\mathrm{Cu}_{\text {cage }}$ and $\mathrm{Cu}_{\text {cage }}-\mathrm{Cu}_{\text {cage }}$ bonding arise. This MO can be identified as the $1 \mathrm{~S}$ jellium orbital ${ }^{10}$ containing the 2 electrons of the superatom $\mathbf{1}^{\prime} \cdot{ }^{10}$ In the case of $\mathrm{X}=\mathrm{Cl}$, the occupied halide a)

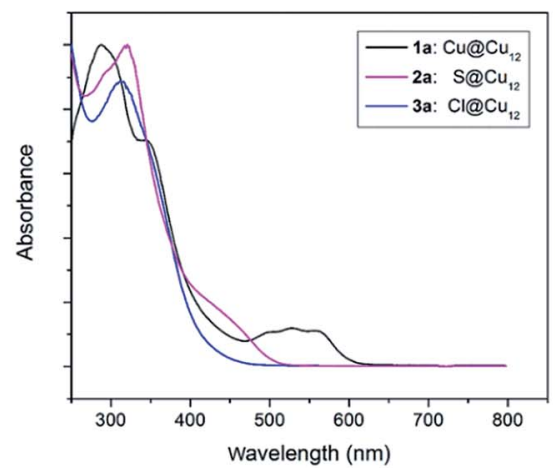

b)

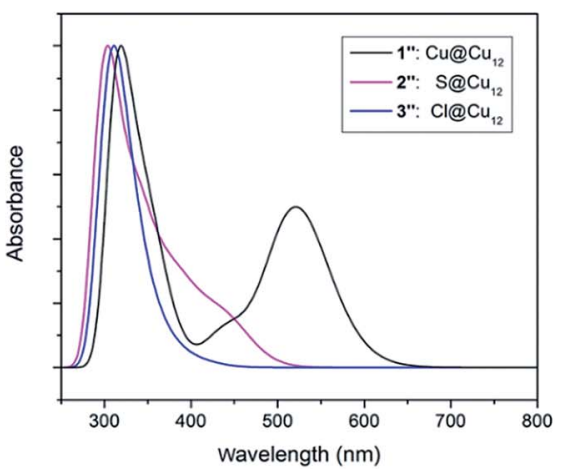

Fig. 6 (a) Experimental UV-vis absorption spectra of the clusters 1-3. (b) TDDFT-simulated UV-vis absorption spectra of the clusters $1^{\prime \prime}-3^{\prime \prime}$.

Table 3 Selected computed data

\begin{tabular}{|c|c|c|c|c|c|c|c|c|}
\hline $\mathbf{1}^{\prime}\left(T_{\mathrm{d}}\right)$ & $\mathrm{Cu}$ & 3.08 & 2.666 & 0.061 & $2.595-2.725$ & $0.047-0.050$ & -0.54 & +0.69 \\
\hline $2^{\prime}\left(T_{\mathrm{d}}\right)$ & $S$ & 3.56 & 2.674 & 0.047 & $2.619-2.728$ & $0.033-0.034$ & -1.61 & +0.74 \\
\hline $2^{\prime \prime}\left(C_{1}\right)$ & $\mathrm{S}$ & 3.53 & $2.747[2.371-3.018]$ & $0.049[0.014-0.104]$ & $2.532-3.276$ & $0.008-0.048$ & -1.59 & +0.75 \\
\hline $3^{\prime}\left(T_{\mathrm{d}}\right)$ & $\mathrm{Cl}$ & 3.84 & 2.899 & 0.023 & $2.707-3.085$ & $0.019-0.036$ & -0.82 & +0.75 \\
\hline $\mathbf{5}^{\prime}\left(C_{3 \mathrm{v}}\right)$ & $\mathrm{Cl}$ & 3.72 & $2.931[2.791-3.071]$ & $0.024[0.017-0.036]$ & $2.719-3.133$ & $0.012-0.040$ & -0.81 & +0.74 \\
\hline $\mathbf{6}^{\prime}\left(T_{\mathrm{d}}\right)$ & $\mathrm{Cl}$ & 4.07 & 2.971 & 0.026 & $2.829-3.111$ & $0.039-0.054$ & -0.80 & +0.70 \\
\hline
\end{tabular}

${ }^{a} \mathrm{Cu}$ from the $\mathrm{Cu}_{12}$ cuboctahedron. ${ }^{b}$ In the $T_{\mathrm{d}}$ symmetry, there are two symmetry-independent cuboctahedral Cu-Cu edges. ${ }^{c}$ WI: Wiberg index. ${ }^{d} q$ : Natural atomic charge. 


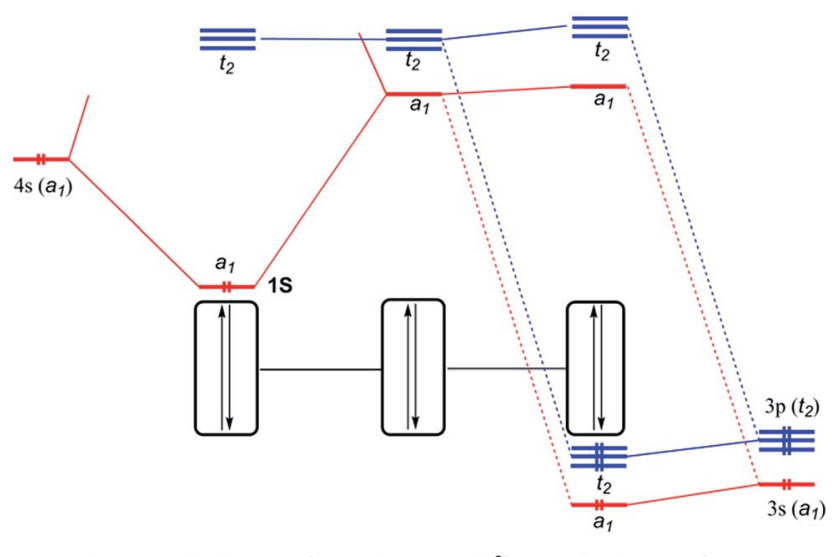

$\left(\mu_{12}-^{-} \mathrm{Cu}^{\prime}\right) \quad\left[\mathrm{Cu}_{13}(\mathrm{dtc})_{6}\left(\mathrm{CCR}^{\prime}\right)_{4}\right]^{+} \quad\left[\mathrm{Cu}_{12}(\mathrm{dtc})_{6}\left(\mathrm{CCR}^{\prime}\right)_{4}\right]^{2+}\left[\mathrm{Cu}_{12} \mathrm{Cl}(\mathrm{dtc})_{6}\left(\mathrm{CCR}^{\prime}\right)_{4}\right]^{+} \quad\left(\mu_{12}-\mathrm{Cl}^{*}\right)$

Fig. 7 Simplified $\mathrm{MO}$ interaction diagram illustrating the strength of the covalent interaction between the $\left[\mathrm{Cu}_{12}(\mathrm{dtc})_{6}\left(\mathrm{CCR}^{\prime}\right)_{4}\right]^{2+}$ cage and its host: left: $\mathrm{Cu}^{-}$, strong; right $\mathrm{Cl}^{-}$, weak (ideal $T_{\mathrm{d}}$ symmetry assumed).

valence $3 \mathrm{~s}$ and $3 p$ orbitals can interact with the $a_{1}$ and $t_{2}$ accepting orbitals of the cage. However, because of the poor energy match between the interacting orbitals, the covalent interaction is weak. Thus, in the case of $\mathrm{X}=$ halogen or chalcogen, the host-guest bonding is dominated by its ionic component. Similar structural and bonding conclusions can be drawn for $\mathbf{5}^{\prime}$ (simplified model for 5a) and the hypothetical $\left[\mathrm{Cu}_{12}\left(\mu_{12}-\mathrm{Cl}\right)(\mathrm{dtc})_{6} \mathrm{Cl}_{4}\right]^{+}\left(6^{\prime}\right)$.

In order to better reproduce the electronic properties of the experimental alkynyl ligands, models with $\mathrm{CCR}^{\prime}=\mathrm{CC}(\mathrm{COOH})$ were also computed, keeping dtc $=\mathrm{S}_{2} \mathrm{CNH}_{2}$. These models, namely $\mathbf{1}^{\prime \prime}, \mathbf{2}^{\prime \prime}$ and $\mathbf{3}^{\prime \prime}$, were considered for $\mathrm{X}=\mathrm{Cu}, \mathrm{S}$ and $\mathrm{Cl}$, respectively. Interestingly, the resulting optimized structures exhibited distorted geometries of $C_{1}$ symmetry (see Table 3 ). Whereas the distortion remains small in the case of $\mathbf{1}^{\prime \prime}$, it is substantially larger for $2^{\prime \prime}$ and $3^{\prime \prime}$. This is exemplified by the large dispersion of the $\mathrm{Cu}-\mathrm{X}$ distances in $2^{\prime \prime}$ and $3^{\prime \prime}(\sim 2.4-3.0 \AA$ and $\sim 2.7-3.3 \AA$, respectively), as compared to that in $\mathbf{1}^{\prime \prime}(\sim 2.6-$ $2.7 \AA$ ). Nevertheless, the averaged values computed for $\mathbf{1}^{\prime \prime}-\mathbf{3}^{\prime \prime}$ (Table 3) are very close to that of the symmetrical $\mathbf{1}^{\prime}-\mathbf{3}^{\prime}$ models. So are also the X NAO charges. It is noteworthy that the distortions away from ideal $T_{\mathrm{d}}$ symmetry afforded by $2^{\prime \prime}-3^{\prime \prime}$ are not equivalent to those exhibited by the clusters 2 and 3 reported in Table 2. These distortions appear rather random and likely result principally from steric and/or crystal packing forces in the investigated clusters. The fact that in solution clusters 24 show only one set of ligands (in line with $T_{\mathrm{d}}$ symmetry) at the NMR time scale is consistent with the primarily ionic character of the bonding between the encapsulated halide or chalcogenide and its $\left[\mathrm{Cu}_{12}\right]^{12+}$ cage, as well as with the weak $\mathrm{Cu}^{+}-\mathrm{Cu}^{+}$ interaction along the cuboctahedral edges. As a whole, our experimental and computed data indicate that clusters of the type 2-4 have a soft flexible shape resulting from the ionic, nondirected, nature of their host-guest interaction.

Time-dependent DFT (TD-DFT) calculations were performed to simulate the UV-vis spectra of clusters 1-3. Because of their high symmetry, the spectra obtained for the $\mathbf{1}^{\prime}-\mathbf{3}^{\prime} T_{\mathrm{d}}$ models (Fig. S14†) are more structured than that of their $\mathbf{1}^{\prime \prime}-\mathbf{3}^{\prime \prime}$ homologs (Fig. 6b), the latter being thus closer to the experimental ones (Fig. 6a). The low-energy band observed for 1a at $540 \mathrm{~nm}$ is computed at $538 \mathrm{~nm}$ for $\mathbf{1}^{\prime}$ and corresponds to a HOMO $\left(\mathrm{a}_{1}\right)$-LUMO $\left(\mathrm{t}_{2}\right)$ transition, a mixture of MMCT and MLCT $(\mathrm{L}=\mathrm{dtc})$ characters. As illustrated above in Fig. 7 , the $1 \mathrm{~S}$ HOMO present in $\mathbf{1}^{\prime}$ does not exist in the halide- or chalcogenide-centered species. Consequently, the latter cannot exhibit the same low-energy band. The band observed for $2 \mathbf{a}$ at $450 \mathrm{~nm}$ corresponds to a HOMO $\left(\mathrm{t}_{2}\right) \rightarrow$ LUMO $\left(\mathrm{t}_{2}\right)$ transition computed at $446 \mathrm{~nm}$ for $2^{\prime}$. It is of MLCT $(\mathrm{L}=\mathrm{dtc})$ nature. A similar low-energy MLCT transition is computed at $390 \mathrm{~nm}$ for $\mathbf{3}^{\prime}$. For the three models, the major transitions of higher energy are mainly of MLCT character.

\section{Conclusions}

In summary, we have isolated and fully characterized $\left[\mathrm{Cu}_{13}(\text { alkynyl })_{4}(\mathrm{dtc})_{6}\right]\left(\mathrm{PF}_{6}\right)$ clusters, the first copper-centred cuboctahedral copper NCs, a miniature of the bulk copper $f c c$ structure, with partial $\mathrm{Cu}(0)$ character confirmed by XANES. Furthermore, they have been reacted to synthesize novel chalcogen- and halogen-centered cuboctahedral copper clusters $\left[\mathrm{Cu}_{12}\left(\mu_{12}-\mathrm{X}\right)(\text { alkynyl })_{4}(\mathrm{dtc})_{6}\right]^{z+}(\mathrm{E}=\mathrm{Cl}, \mathrm{Br}, \mathrm{S})$. These clusters are the first examples of compounds in which a sulfide, chloride or bromide ion holds a so large coordination number (12). Prior to this report, the highest coordination number for sulfur and bromine was nine, and eight for chlorine. Bonding interactions between the $\mathrm{Cu}_{12}$ cuboctahedral cage and the encapsulated element $(\mathrm{X})$, rationalized by DFT calculations, indicate that the covalent component of the host-guest bonding interaction decreases as $\mathrm{Cu}>\mathrm{S}>\mathrm{Br} \approx \mathrm{Cl}$. While the nature of the lowenergy band observed for 1a can be reasonably assigned as a mixture of MMCT and MLCT $(\mathrm{L}=\mathrm{dtc})$ characters, it is primarily MLCT transition ( $\mathrm{L}=\mathrm{dtc}$ ) for 2 and 3. Strikingly, new compounds have been prepared via replacing alkynyl with chloride. This synthetic methodology may open an avenue for the rational synthesis of organometallic compounds other than the spontaneous self-assembly. The new compounds synthesized are well characterized and the physical properties are explained by both theory and experimental methods.

\section{Experimental section}

\section{General procedures and instrumentation}

All chemicals were purchased from commercial sources and used as received. Solvents were purified following standard protocols. All reactions were performed in oven-dried Schlenk glassware using standard inert atmosphere techniques. All reactions were carried out in a $\mathrm{N}_{2}$ atmosphere by using standard Schlenk techniques. $\left[\mathrm{Cu}_{28} \mathrm{H}_{15}\left(\mathrm{~S}_{2} \mathrm{CN}^{n} \mathrm{Bu}_{2}\right)_{12}\right] \mathrm{PF}_{6}$ was prepared by a slightly modified procedure reported previously in the literature and characterized. ${ }^{19}$ NMR spectra were recorded on a Bruker Advance DPX300 FT-NMR spectrometer operating at $300 \mathrm{MHz}$. The chemical shift $(\delta)$ and coupling constant $(J)$ are reported in ppm and $\mathrm{Hz}$, respectively. ${ }^{31} \mathrm{P}$ NMR spectra were referenced to external $85 \% \mathrm{H}_{3} \mathrm{PO}_{4}$ at $\delta 0.00$. The ESI-mass spectrum was recorded on a Fison Quattro Bio-Q (Fisons 
Instruments, VG Biotech, UK). XANES spectra at the Cu K-edge were recorded in transmission mode at beamline TLS-17C1 of the National Synchrotron Radiation Research Center (NSRRC), Taiwan. The electron storage ring was operated at $1.5 \mathrm{GeV}$ with a beam current of $360 \mathrm{~mA}$ under top-up injection. A doublecrystal $\mathrm{Si}(111)$ monochromator was employed for energy scanning. Incident and transmitted beam intensities were measured using gas-filled ionization chambers. An appropriate amount of each sample was adopted to reach the optimal thickness with the spectral edge jump being roughly unity. A standard $\mathrm{Cu}$ foil was measured simultaneously by using a third ionization chamber so that energy calibration could be performed scan by scan.

\section{General synthetic method for the isolation of 1}

In a flame-dried Schlenk tube, $\left[\mathrm{Cu}_{28}(\mathrm{H})_{15}\left(\mathrm{~S}_{2} \mathrm{CNR}_{2}\right)_{12}\right]\left(\mathrm{PF}_{6}\right)(0.1$ mmol) was suspended in THF $\left(5 \mathrm{~cm}^{3}\right)$ along with the terminal alkyne $(1 \mathrm{mmol})$ and the resulting mixture was stirred at $30{ }^{\circ} \mathrm{C}$ for $24 \mathrm{~h}$. The solvent was evaporated under vacuum and the residue was washed with diethyl ether $(3 \times 5 \mathrm{~mL})$ to remove impurities from the ligand and the dark red residue was extracted in methanol. Finally, the solvent was evaporated to dryness under vacuum to get $\mathbf{1}$ as a pure powder in $40-70 \%$ yields. In this reaction, the corresponding alkene and $\left[\mathrm{Cu}_{8^{-}}\right.$ $\left.\mathrm{H}\left(\mathrm{S}_{2} \mathrm{CNR}_{2}\right)_{6}\right] \mathrm{PF}_{6}$ were produced as by-products.

$\left[\mathbf{C u}_{13}\left(\mathbf{S}_{2} \mathbf{C N}^{n} \mathbf{B u}_{2}\right)_{6}(\mathbf{C} \equiv \mathbf{C C O O E t})_{4}\right] \mathbf{P F}_{6} \quad$ (1b). (0.150 g, 42\%, based on $\mathrm{Cu}$ ): ESI-MS: $m / z 2438.6\left(\mathrm{M}^{+}\right) .{ }^{1} \mathrm{H}$ NMR $(300 \mathrm{MHz}$, $\left.\mathrm{CDCl}_{3}\right): 4.15\left(\mathrm{br}, 8 \mathrm{H}, \mathrm{OCH}_{2}\right), 4.02\left(\mathrm{t}, 24 \mathrm{H}, \mathrm{NCH}_{2}\right), 1.79(\mathrm{br}, 24 \mathrm{H}$, $\mathrm{CH}_{2}$ ), 1.36 (br, 24H, $\mathrm{CH}_{2} \mathrm{CH}_{3}$ ), 1.27 (t, $\left.12 \mathrm{H}, \mathrm{OCH}_{2} \mathrm{CH}_{3}\right), 0.94$ (t, $\left.36 \mathrm{H}, \mathrm{CH}_{3}\right) \mathrm{ppm} ;{ }^{13} \mathrm{C} \mathrm{NMR}\left(300 \mathrm{MHz}, \mathrm{CDCl}_{3}\right): 203.6,152.7,78.2$, 74.8, 62.8, 52.1, 29.2, 20.1, 14.2, 13.7; ${ }^{31} \mathrm{P}$ NMR $(300 \mathrm{MHz}$, $\left.\mathrm{CDCl}_{3}\right)$ : $-143.5 \mathrm{ppm}$; FT-IR data in $\mathrm{KBr}$ pellet $\left(\mathrm{cm}^{-1}\right): 2972.1$, 1503, 942, 843.

$\left[\mathbf{C u}_{13}\left(\mathbf{S}_{2} \mathbf{C N}^{\mathrm{i}} \mathbf{P r}_{2}\right)_{\mathbf{6}}(\mathbf{C} \equiv \mathbf{C C O O E t})_{4}\right] \mathbf{P F}_{\mathbf{6}} \quad(\mathbf{1 c}) . \quad(0.150 \quad \mathrm{~g}, \quad 65 \%$, based on $\mathrm{Cu}$ ): ESI-MS: $m / z 2270.3\left(\mathrm{M}^{+}\right) .{ }^{1} \mathrm{H}$ NMR $(300 \mathrm{MHz}$, $\mathrm{CDCl}_{3}$ ): $5.96(\mathrm{br}, 6 \mathrm{H}, \mathrm{NCH}), 4.18(\mathrm{br}, 6 \mathrm{H}, \mathrm{NCH}), 3.95(\mathrm{br}, 8 \mathrm{H}$, $\mathrm{OCH}_{2}$ ), $1.63\left(\mathrm{br}, 36 \mathrm{H}, \mathrm{CH}_{3}\right), 1.31\left(\mathrm{br}, 36 \mathrm{H}, \mathrm{CH}_{3}\right), 1.29(\mathrm{t}, 12 \mathrm{H}$, $\left.\mathrm{OCH}_{2} \mathrm{CH}_{3}\right) \mathrm{ppm} ;{ }^{13} \mathrm{C} \mathrm{NMR}\left(300 \mathrm{MHz}, \mathrm{CDCl}_{3}\right): 201.2,152.5,78.5$, 74.8, 62.6, 57.6, 20.5, 13.6; ${ }^{31} \mathrm{P}$ NMR (300 $\left.\mathrm{MHz}, \mathrm{CDCl}_{3}\right)$ : -143.5 ppm; FT-IR data in $\mathrm{KBr}$ pellet $\left(\mathrm{cm}^{-1}\right)$ : 2961.1, 2931.7, 2872.7, 2009.1, 1594.0, 1498.4, 1233.3, 1143.2, 1080.0, 1027.5, 941.4, 835.3, 719.8, 557.2.

$\left[\mathrm{Cu}_{13}\left(\mathbf{S}_{2} \mathbf{C N}^{n} \mathbf{P r}_{2}\right)_{6}\left\{\mathbf{C} \equiv \mathbf{C C}_{6} \mathbf{H}_{3}\left(\mathbf{C F}_{3}\right)_{2}\right\}_{4}\right] \mathbf{P F}_{\mathbf{6}}$ (1d). (0.150 g, 55\%, based on $\mathrm{Cu})$ : ESI-MS: $m / z 2830.3\left(\mathrm{M}^{+}\right) .{ }^{1} \mathrm{H}$ NMR $\left(\mathrm{CDCl}_{3}\right): 7.87$ (br, 12H, $\mathrm{ArH}$ ), 3.95 (br, 24H, $\mathrm{NCH}_{2}$ ), 1.86 (br, 24H, $\mathrm{CH}_{2} \mathrm{CH}_{3}$ ), $0.96\left(\mathrm{t}, 36 \mathrm{H}, \mathrm{CH}_{3}\right) \mathrm{ppm} ;{ }^{13} \mathrm{C} \mathrm{NMR}\left(300 \mathrm{MHz}, \mathrm{CDCl}_{3}\right): 200.8$, 132.7, 130.9, 123.3, 122.8, 88.5, 78.2, 55.7, 20.3, 12.2; ${ }^{31} \mathrm{P}$ NMR $\left(\mathrm{CDCl}_{3}\right):-143.5 \mathrm{ppm}$; FT-IR data in $\mathrm{KBr}$ pellet $\left(\mathrm{cm}^{-1}\right): 2972.1$, 1503, 942, 843 .

\section{General synthetic method for the isolation of 2}

In a flame-dried Schlenk tube, $\left[\mathrm{Cu}_{13}\left(\mathrm{~S}_{2} \mathrm{CNR}_{2}\right)_{6}\left(\mathrm{C} \equiv \mathrm{CR}^{\prime}\right)_{4}\right]\left(\mathrm{PF}_{6}\right)$ $(0.1 \mathrm{mmol})$ was suspended in THF $\left(5 \mathrm{~cm}^{3}\right)$ along with $\mathrm{K}\left[\mathrm{S}_{2} \mathrm{CNR}_{2}\right]$ $(0.22 \mathrm{mmol})$ and the resulting mixture was stirred at $0{ }^{\circ} \mathrm{C}$ for $24 \mathrm{~h}$. The solvent was evaporated under vacuum and the desired compound was extracted in diethyl ether. Finally, the solvent was evaporated to dryness under vacuum to get 2 as a pure orange powder in $20-30 \%$ yields.

$\left[\mathbf{C u}_{12}\left(\boldsymbol{\mu}_{12}-\mathbf{S}\right)\left(\mathbf{S}_{2} \mathbf{C N}^{n} \mathbf{B u}_{2}\right)_{6}(\mathbf{C} \equiv \mathbf{C C O O M e})_{4}\right] \quad(2 a)$. ESI-MS: $\mathrm{m} / z$ $2351.6\left(\mathrm{M}^{+}\right) .{ }^{1} \mathrm{H}$ NMR $\left(300 \mathrm{MHz}, \mathrm{CDCl}_{3}\right): 4.03$ (t, 24H, $\mathrm{NCH}_{2}$ ), $3.73\left(\mathrm{~s}, 12 \mathrm{H}, \mathrm{OCH}_{3}\right), 1.80\left(\mathrm{br}, 24 \mathrm{H}, \mathrm{CH}_{2}\right), 1.40\left(\mathrm{br}, 24 \mathrm{H}, \mathrm{CH}_{2} \mathrm{CH}_{3}\right)$, $0.99\left(\mathrm{t}, 36 \mathrm{H}, \mathrm{CH}_{3}\right) \mathrm{ppm} ;{ }^{13} \mathrm{C} \mathrm{NMR}\left(300 \mathrm{MHz}, \mathrm{CDCl}_{3}\right): 203.4$, 152.5, 96.6, 84.5, 54.2, 51.9, 28.8, 20.2, 14.0; FT-IR data in $\mathrm{KBr}$ pellet $\left(\mathrm{cm}^{-1}\right):$ 2962.2, 2937.2, 2874.3, 2015.1, 1694.3, 1502.3, 1297.7, 1218.2, 929.0, 845.3.

$\left[\mathrm{Cu}_{12}\left(\boldsymbol{\mu}_{12}-\mathrm{S}\right)\left(\mathbf{S}_{2} \mathbf{C N}^{n} \mathbf{B u}_{2}\right)_{6}(\mathbf{C} \equiv \mathbf{C C O O E t})_{4}\right](2 \mathrm{~b}) .(0.150 \mathrm{~g}, 42 \%$, based on $\mathrm{Cu})$ : ESI-MS: $m / z 2407.5\left(\mathrm{M}^{+}\right) .{ }^{1} \mathrm{H}$ NMR $(300 \mathrm{MHz}$, $\left.\mathrm{CDCl}_{3}\right): 4.14\left(\mathrm{br}, 8 \mathrm{H}, \mathrm{OCH}_{2}\right), 4.02\left(\mathrm{t}, 24 \mathrm{H}, \mathrm{NCH}_{2}\right), 1.78(\mathrm{br}, 24 \mathrm{H}$, $\mathrm{CH}_{2}$ ), 1.37 (br, 24H, $\mathrm{CH}_{2} \mathrm{CH}_{3}$ ), 1.27 (t, 12H, $\left.\mathrm{OCH}_{2} \mathrm{CH}_{3}\right), 0.95$ (t, $\left.36 \mathrm{H}, \mathrm{CH}_{3}\right) \mathrm{ppm} ;{ }^{13} \mathrm{C} \mathrm{NMR}\left(300 \mathrm{MHz}, \mathrm{CDCl}_{3}\right): 203.8,152.6,78.5$, 74.7, 62.7, 51.9, 28.9, 19.8, 14.4, 13.5; FT-IR data in $\mathrm{KBr}$ pellet $\left(\mathrm{cm}^{-1}\right):$ 2972.1, 1503, 942, 843.

$\left[\mathbf{C u}_{12}\left(\mu_{12}-\mathbf{S}\right)\left(\mathbf{S}_{2} \mathbf{C N}^{\mathrm{i}} \mathbf{P r}_{2}\right)_{\mathbf{6}}(\mathbf{C} \equiv \mathbf{C C O O E t})_{4}\right]$ (2c). (0.150 g, 65\%, based on $\mathrm{Cu})$ : ESI-MS: $m / z 2239.0\left(\mathrm{M}^{+}\right) .{ }^{1} \mathrm{H}$ NMR $(300 \mathrm{MHz}$, $\mathrm{CDCl}_{3}$ ): $5.92(\mathrm{br}, 6 \mathrm{H}, \mathrm{NCH}), 4.10(\mathrm{br}, 6 \mathrm{H}, \mathrm{NCH}), 3.92(\mathrm{br}, 8 \mathrm{H}$, $\mathrm{OCH}_{2}$ ), 1.69 (br, 36H, $\mathrm{CH}_{3}$ ), $1.30\left(\mathrm{br}, 36 \mathrm{H}, \mathrm{CH}_{3}\right), 1.26(\mathrm{t}, 12 \mathrm{H}$, $\left.\mathrm{OCH}_{2} \mathrm{CH}_{3}\right) \mathrm{ppm} ;{ }^{13} \mathrm{C} \mathrm{NMR}\left(300 \mathrm{MHz}, \mathrm{CDCl}_{3}\right): 200.7,152.1,78.8$, 74.8, 62.3, 57.8, 21.2, 13.4; FT-IR data in $\mathrm{KBr}$ pellet $\left(\mathrm{cm}^{-1}\right)$ : 2961.1, 2931.7, 2872.7, 2009.1, 1594.0, 1498.4, 1233.3, 1143.2, 1080.0, 1027.5, 941.4, 835.3, 719.8, 557.2.

\section{General synthetic method for the isolation of 3}

In a flame-dried Schlenk tube, $\left[\mathrm{Cu}_{13}\left(\mathrm{~S}_{2} \mathrm{CNR}_{2}\right)_{6}\left(\mathrm{C} \equiv \mathrm{CR}^{\prime}\right)_{4}\right]\left(\mathrm{PF}_{6}\right)$ (0.1 mmol) was suspended in $\mathrm{CH}_{2} \mathrm{Cl}_{2}\left(5 \mathrm{~cm}^{3}\right)$ and the resulting mixture was stirred at room temperature for 3 days. The solvent was evaporated under vacuum and the residue was washed with hexane, diethyl ether and methanol and the yellow residue was extracted in $\mathrm{CH}_{2} \mathrm{Cl}_{2}$. Finally, the solvent was evaporated to dryness and subjected to column chromatography to get 3 as a pure powder in 11-30\% yields. Compound $5 \mathbf{a}$ was isolated as a byproduct in $5 \%$ yield.

An alternative method for the synthesis of $3 \mathrm{e}$ and $4 \mathrm{e}$. In a flame-dried Schlenk tube, $\left[\mathrm{Cu}\left(\mathrm{CH}_{3} \mathrm{CN}\right)_{4}\right] \mathrm{PF}_{6}(0.27 \mathrm{mmol})$ and $\mathrm{K}\left[\mathrm{S}_{2} \mathrm{CN}^{n} \mathrm{Bu}_{2}\right](0.12 \mathrm{mmol})$ were suspended in $15 \mathrm{~mL}$ THF solvent. To this suspension $\mathrm{HC} \equiv \mathrm{CPh}(0.08 \mathrm{mmol})$ and few drops of triethylamine were added and the reaction mixture was stirred at $0{ }^{\circ} \mathrm{C}$ for 10 minutes. To the reaction mixture, $\mathrm{Bu}_{4} \mathrm{NX}(0.02$ mmol) was added and stirred for 12 hours. The solvent was evaporated and the residue was washed with hexane, ether and methanol. The yellow residue was extracted in dichloromethane and purified by passing through alumina, which yielded $3 \mathbf{e}$ and $\mathbf{4 e}$ in 45 and $52 \%$ yields respectively.

$\left[\mathrm{Cu}_{12}\left(\mu_{12}-\mathrm{Cl}\right)\left(\mathrm{S}_{2} \mathrm{CN}^{n} \mathrm{Bu}_{2}\right)_{6}\left(\mathrm{C} \equiv \mathrm{CCOOMe}_{4}\right] \mathrm{PF}_{6} \quad\right.$ (3a). ESI-MS: $m / z 2354.8\left(\mathrm{M}^{+}\right) .{ }^{1} \mathrm{H}$ NMR $\left(300 \mathrm{MHz} \mathrm{CDCl}_{3}\right): 4.04(\mathrm{t}, 24 \mathrm{H}$, $\left.\mathrm{NCH}_{2}\right), 3.71\left(\mathrm{~s}, 12 \mathrm{H}, \mathrm{OCH}_{3}\right), 1.79\left(\mathrm{br}, 24 \mathrm{H}, \mathrm{CH}_{2}\right), 1.41(\mathrm{br}, 24 \mathrm{H}$, $\mathrm{CH}_{2} \mathrm{CH}_{3}$ ), 0.98 (t, 36H, $\left.\mathrm{CH}_{3}\right) \mathrm{ppm} ;{ }^{13} \mathrm{C} \mathrm{NMR}\left(300 \mathrm{MHz}, \mathrm{CDCl}_{3}\right.$ ): 203.7, 150.2 , 98.2, 81.8, 51.7, 53.0, 29.2, 21.1, 13.4; ${ }^{31} \mathrm{P}$ NMR (300 $\left.\mathrm{MHz}, \mathrm{CDCl}_{3}\right)$ : $-143.5 \mathrm{ppm}$; FT-IR data in $\mathrm{KBr}$ pellet $\left(\mathrm{cm}^{-1}\right)$ : 2960.2, 2937.0, 2873.5, 2017.5, 1690.4, 1498.2, 1292.4, 1220.6, 928.5, 844.6.

$\left[\mathrm{Cu}_{12}\left(\boldsymbol{\mu}_{12}-\mathbf{C l}\right)\left(\mathbf{S}_{2} \mathbf{C N}^{n} \mathbf{B u}_{2}\right)_{6}(\mathbf{C} \equiv \mathbf{C C O O E t})_{4}\right] \mathbf{P F}_{6} \quad(3 \mathrm{~b}) . \quad(0.150 \mathrm{~g}$, $42 \%$, based on $\mathrm{Cu}$ ): ESI-MS: $m / z 2410.7\left(\mathrm{M}^{+}\right) .{ }^{1} \mathrm{H}$ NMR $(300 \mathrm{MHz}$, 
$\left.\mathrm{CDCl}_{3}\right): 4.15\left(\mathrm{br}, 8 \mathrm{H}, \mathrm{OCH}_{2}\right), 4.03\left(\mathrm{t}, 24 \mathrm{H}, \mathrm{NCH}_{2}\right), 1.80(\mathrm{br}, 24 \mathrm{H}$, $\mathrm{CH}_{2}$ ), 1.37 (br, 24H, $\mathrm{CH}_{2} \mathrm{CH}_{3}$ ), 1.26 (t, $\left.12 \mathrm{H}, \mathrm{OCH}_{2} \mathrm{CH}_{3}\right), 0.95$ (t, $\left.36 \mathrm{H}, \mathrm{CH}_{3}\right) \mathrm{ppm} ;{ }^{13} \mathrm{C} \mathrm{NMR}\left(300 \mathrm{MHz}, \mathrm{CDCl}_{3}\right): 201.5,153.5,77.9$, 74.5, 62.6, 52.0, 28.9, 20.2, 14.3, 13.3; ${ }^{31} \mathrm{P}$ NMR $(300 \mathrm{MHz}$, $\left.\mathrm{CDCl}_{3}\right)$ : $-143.5 \mathrm{ppm}$; FT-IR data in $\mathrm{KBr}$ pellet $\left(\mathrm{cm}^{-1}\right): 2972.1$, 1503, 942, 843.

$\left[\mathbf{C u}_{12}\left(\boldsymbol{\mu}_{12}-\mathbf{C l}\right)\left(\mathbf{S}_{2} \mathbf{C N}^{\mathrm{i}} \mathbf{P r}_{2}\right)_{\mathbf{6}}(\mathbf{C} \equiv \mathbf{C C O O E t})_{4}\right] \mathbf{P F}_{\mathbf{6}} \quad(3 \mathrm{c}) . \quad(0.150 \mathrm{~g}$, 65\%, based on $\mathrm{Cu})$ : ESI-MS: $m / z 2242.5\left(\mathrm{M}^{+}\right) .{ }^{1} \mathrm{H}$ NMR $(300 \mathrm{MHz}$, $\mathrm{CDCl}_{3}$ ): $5.95(\mathrm{br}, 6 \mathrm{H}, \mathrm{NCH}), 4.16(\mathrm{br}, 6 \mathrm{H}, \mathrm{NCH}), 4.10(\mathrm{br}, 8 \mathrm{H}$, $\mathrm{OCH}_{2}$ ), 1.65 (br, 36H, $\mathrm{CH}_{3}$ ), $1.30\left(\mathrm{br}, 36 \mathrm{H}, \mathrm{CH}_{3}\right), 1.28(\mathrm{t}, 12 \mathrm{H}$, $\left.\mathrm{OCH}_{2} \mathrm{CH}_{3}\right) \mathrm{ppm} ;{ }^{13} \mathrm{C} \mathrm{NMR}\left(300 \mathrm{MHz}, \mathrm{CDCl}_{3}\right): 202.1$, 151.6, 78.7, 74.5, 62.3, 57.5, 20.6, 13.7; ${ }^{31} \mathrm{P}$ NMR (300 $\left.\mathrm{MHz}, \mathrm{CDCl}_{3}\right)$ : -143.5 ppm; FT-IR data in $\mathrm{KBr}$ pellet $\left(\mathrm{cm}^{-1}\right)$ : 2961.1, 2931.7, 2872.7, 2009.1, 1594.0, 1498.4, 1233.3, 1143.2, 1080.0, 1027.5, 941.4, 835.3, 719.8, 557.2.

$\left[\mathbf{C u}_{12}\left(\mu_{12}-\mathbf{C l}\right)\left(\mathbf{S}_{2} \mathbf{C N}^{n} \mathbf{P r}_{2}\right)_{6}\left\{\mathbf{C} \equiv \mathbf{C C}_{6} \mathbf{H}_{3}\left(\mathbf{C F}_{3}\right)_{2}\right\}_{4}\right] \mathbf{P F}_{6}$

(3d). (0.150 g, 55\%, based on Cu): ESI-MS: $m / z 2802.3\left(\mathrm{M}^{+}\right) .{ }^{1} \mathrm{H}$ NMR (300 MHz, $\mathrm{CDCl}_{3}$ ): 7.88 (br, 12H, $\mathrm{ArH}$ ), 3.95 (br, 24H, $\mathrm{NCH}_{2}$ ), 1.85 (br, 24H, $\left.\mathrm{CH}_{2} \mathrm{CH}_{3}\right), 0.98\left(\mathrm{t}, 36 \mathrm{H}, \mathrm{CH}_{3}\right) \mathrm{ppm} ;{ }^{13} \mathrm{C} \mathrm{NMR}(300$ $\left.\mathrm{MHz}, \mathrm{CDCl}_{3}\right):$ 199.8, 132.8, 131.6, 123.5, 123.0, 88.9, 78.6, 55.5, 20.2, 11.9; ${ }^{31} \mathrm{P}$ NMR (300 $\left.\mathrm{MHz}, \mathrm{CDCl}_{3}\right)$ : $-143.5 \mathrm{ppm}$; FT-IR data in $\mathrm{KBr}$ pellet $\left(\mathrm{cm}^{-1}\right): 2972.1,1503,942,843$.

$\left[\mathbf{C u}_{12}\left(\boldsymbol{\mu}_{12}-\mathbf{C l}\right)\left(\mathbf{S}_{2} \mathbf{C N}^{n} \mathbf{B u}_{2}\right)_{6}(\mathbf{C} \equiv \mathbf{C P h})_{4}\right] \mathbf{P F}_{6} \quad$ (3e). $\quad$ ESI-MS: $m / z$ $2426.4\left(\mathrm{M}^{+}\right) .{ }^{1} \mathrm{H}$ NMR $\left(300 \mathrm{MHz}, \mathrm{CDCl}_{3}\right): 7.15-7.56(\mathrm{~m}, 20 \mathrm{H}$, $\left.\mathrm{C}_{6} \mathrm{H}_{5}\right), 3.81\left(\mathrm{t}, 24 \mathrm{H}, \mathrm{NCH}_{2}\right), 1.62\left(\mathrm{br}, 24 \mathrm{H}, \mathrm{CH}_{2}\right), 1.26(\mathrm{br}, 24 \mathrm{H}$, $\mathrm{CH}_{2} \mathrm{CH}_{3}$ ), 0.82 (t, 36H, $\mathrm{CH}_{3}$ ), ppm; ${ }^{13} \mathrm{C} \mathrm{NMR} \mathrm{(300} \mathrm{MHz,} \mathrm{CDCl}_{3}$ ): 202.5, 131.4, 128.1, 124.2, 59.4, 29.2, 20.4, 13.9; ${ }^{31} \mathrm{P}$ NMR (300 $\left.\mathrm{MHz}, \mathrm{CDCl}_{3}\right)$ : $-143.5 \mathrm{ppm}$; FT-IR data in CsI pellet $\left(\mathrm{cm}^{-1}\right)$ : 2957.8, 2931.8, 2887.8, 2018.9, 1739.4, 1502.2, 1292.6, 1220.5, 926.8, 843.4.

$\left[\mathbf{C u}_{12}\left(\boldsymbol{\mu}_{12}-\mathbf{B r}\right)\left(\mathbf{S}_{2} \mathbf{C N}^{n} \mathbf{B u}_{2}\right)_{6}(\mathbf{C} \equiv \mathbf{C P h})_{4}\right] \mathbf{P F}_{6} \quad$ (4e). ESI-MS: $\mathrm{m} / z$ $2470.5\left(\mathrm{M}^{+}\right) .{ }^{1} \mathrm{H}$ NMR $\left(300 \mathrm{MHz}, \mathrm{CDCl}_{3}\right): 7.15-7.56(\mathrm{~m}, 20 \mathrm{H}$, $\left.\mathrm{C}_{6} H_{5}\right), 3.81\left(\mathrm{t}, 24 \mathrm{H}, \mathrm{NCH}_{2}\right), 1.62\left(\mathrm{br}, 24 \mathrm{H}, \mathrm{CH}_{2}\right), 1.26(\mathrm{br}, 24 \mathrm{H}$, $\left.\mathrm{CH}_{2} \mathrm{CH}_{3}\right), 0.82\left(\mathrm{t}, 36 \mathrm{H}, \mathrm{CH}_{3}\right), \mathrm{ppm} ;{ }^{13} \mathrm{C} \mathrm{NMR} \mathrm{(300} \mathrm{MHz,} \mathrm{CDCl}_{3}$ ): 202.0, 131.6, 128.4, 124.2, 58.9, 28.8, 20.4, 14.2; ${ }^{31} \mathrm{P}$ NMR (300 $\left.\mathrm{MHz}, \mathrm{CDCl}_{3}\right)$ : $-143.5 \mathrm{ppm}$; FT-IR data in CsI pellet $\left(\mathrm{cm}^{-1}\right)$ : 2959.4, 2932.0, 2889.2, 2020.4, 1739.6, 1502.2, 1292.6, 1220.6, 926.9, 843.4.

$\left[\mathrm{Cu}_{12}\left(\mu_{12}-\mathrm{Cl}\right)\left(\mu_{3}-\mathrm{Cl}\right)\left(\mathrm{S}_{2} \mathrm{CN}^{n} \mathrm{Bu}_{2}\right)_{6}(\mathrm{C} \equiv \mathrm{CCOOMe})_{3}\right]^{+} \quad(5 \mathrm{a}) . \quad$ ESIMS: $m / z 2308.4\left(\mathrm{M}^{+}\right) .{ }^{1} \mathrm{H}$ NMR $\left(300 \mathrm{MHz}, \mathrm{CDCl}_{3}\right): 4.03(\mathrm{t}, 24 \mathrm{H}$, $\mathrm{NCH}_{2}$ ), $3.70\left(\mathrm{~s}, 9 \mathrm{H}, \mathrm{OCH}_{3}\right), 1.79\left(\mathrm{br}, 24 \mathrm{H}, \mathrm{CH}_{2}\right), 1.39(\mathrm{br}, 24 \mathrm{H}$, $\mathrm{CH}_{2} \mathrm{CH}_{3}$ ), 0.97 (t, 36H, $\left.\mathrm{CH}_{3}\right) \mathrm{ppm} ;{ }^{13} \mathrm{C} \mathrm{NMR} \mathrm{(300} \mathrm{MHz,} \mathrm{CDCl}_{3}$ ): 203.5, 150.7, 95.8, 82.7, 54.6, 51.8, 28.8, 21.2, 13.7; ${ }^{31} \mathrm{P}$ NMR (300 $\left.\mathrm{MHz}, \mathrm{CDCl}_{3}\right)$ : -143.5 ppm; FT-IR data in $\mathrm{KBr}$ pellet $\left(\mathrm{cm}^{-1}\right): 2960.6$, 2933.5, 2877.5, 2020.2, 1686.4, 1507.6, 1292.4, 1220.8, 928.7, 842.9.

\section{$\mathrm{X}$-ray structure determination}

Single crystals suitable for X-ray diffraction analysis of $\mathbf{2 a - b}, \mathbf{3 d -}$ e, 4e and 5a were obtained by slowly diffusing hexane into a concentrated dichloromethane/acetone solution at ambient temperature. The single crystals were mounted on the tip of glass fibre coated in paratone oil, then frozen. Data were collected on a Bruker APEX II CCD diffractometer using graphite monochromated Mo $\mathrm{K} \alpha$ radiation $(\lambda=0.71073 \AA)$ at 100 (3d, 3e), 150 (2a, 5a) and 296 (2b, 4e) K. Data reduction was performed with SAINT. ${ }^{20}$ Absorption corrections for the area detector were performed by using the SADABS program. ${ }^{21}$ The structure was solved by direct methods and refined by leastsquares against $F^{2}$ using the SHELXL-2018/3 package, ${ }^{22}$ incorporated in SHELXTL/PC V6.14. ${ }^{23}$ All non-hydrogen atoms were refined anisotropically. Geometric restraints for the $\mathrm{sp}^{3}$ carboncarbon bond of these atoms were applied. In the crystal of $2 \mathbf{a}$, the $\mathrm{C}(\mathrm{O}) \mathrm{OMe}$ motifs on two of four methyl propiolate groups were disordered over two positions with equal occupancy. Structures $\mathbf{2 b}$, $\mathbf{3 e}$ and $\mathbf{4 e}$ contain large solvent-accessible voids, with substantial peaks of electron density visible inside these voids which could be due to the loss of solvent while mounting a single crystal at ambient temperature. In 3d, the cocrystallization of $\left[\mathrm{Cl} @ \mathrm{Cu}_{12}\left(\mathrm{~S}_{2} \mathrm{CN}^{n} \mathrm{Pr}_{2}\right)_{6}\left\{\mathrm{C} \equiv \mathrm{CC}_{6} \mathrm{H}_{3}\left(\mathrm{CF}_{3}\right)_{2}\right\}_{4}\right] \mathrm{PF}_{6}$ and $\left[\mathrm{Cu} @ \mathrm{Cu}_{12}\left(\mathrm{~S}_{2} \mathrm{CN}^{n} \mathrm{Pr}_{2}\right)_{6}\left\{\mathrm{C} \equiv \mathrm{CC}_{6} \mathrm{H}_{3}\left(\mathrm{CF}_{3}\right)_{2}\right\}_{4}\right] \mathrm{PF}_{6}$ was found. The central atom in the $\mathrm{Cu}_{12}$ cuboctahedral cage was refined with $70 \% \mathrm{Cl}$ and $30 \% \mathrm{Cu}$. Cu1 and $\mathrm{Cu} 1 \mathrm{~B}$ are refined with occupancy ratio $0.7: 0.3$. Thus, the composition in crystal $\mathbf{3 d}$ is $\left\{\left[\mathrm{Cl} @ \mathrm{Cu}_{12}\left(\mathrm{~S}_{2} \mathrm{CN}^{n} \mathrm{Pr}_{2}\right)_{6}\left\{\mathrm{C} \equiv \mathrm{CC}_{6} \mathrm{H}_{3}\left(\mathrm{CF}_{3}\right)_{2}\right\}_{4}\right] \mathrm{PF}_{6}\right\}_{0.7}\left\{\left[\mathrm{Cu} @ \mathrm{Cu}_{12}{ }^{-}\right.\right.$ $\left.\left.\left(\mathrm{S}_{2} \mathrm{CN}^{n} \mathrm{Pr}_{2}\right)_{6}\left\{\mathrm{C} \equiv \mathrm{CC}_{6} \mathrm{H}_{3}\left(\mathrm{CF}_{3}\right)_{2}\right\}_{4}\right] \mathrm{PF}_{6}\right\}_{0.3}$. In 5a, eight cationic $\left[\mathrm{Cu}_{12}\left(\mu_{12}-\mathrm{Cl}\right)\left(\mu_{3}-\mathrm{Cl}\right)\left(\mathrm{S}_{2} \mathrm{CN}^{n} \mathrm{Bu}_{2}\right)_{6}(\mathrm{C} \equiv \mathrm{CCOOMe})_{3}\right]^{+}$molecules, four $\mathrm{PF}_{6}{ }^{-}$anions, and four $\mathrm{Cl}^{-}$anions were found in one unit cell. The chloride atom was further disordered at multiple positions. Thus, the composition in crystal $5 \mathbf{a}$ is $\left[\mathrm{Cu}_{12}\left(\mu_{12}-\mathrm{Cl}\right)\left(\mu_{3}-\mathrm{Cl}\right)\left(\mathrm{S}_{2} \mathrm{CN}^{n} \mathrm{Bu}_{2}\right)_{6}{ }^{-}\right.$ $\left.(\mathrm{C} \equiv \mathrm{CCOOMe})_{3}\right]\left(\mathrm{PF}_{6}\right)_{0.5}(\mathrm{Cl})_{0.5}$. CCDC 1501795 (1a), 1815418 (2a), 1815419 (2b), 1815421 (3d), 1815422 (3e), 1815423 (4e) and 1815424 (5a) contain the ESI crystallographic data for this paper. $\dagger$

Crystallographic data of 2a: $\mathrm{C}_{70} \mathrm{H}_{120} \mathrm{Cu}_{12} \mathrm{~N}_{6} \mathrm{O}_{8} \mathrm{~S}_{13}$, orthorhombic, $P 2{ }_{1} 2_{1} 2_{1}, a=18.2449(13) \AA, b=23.2180(15) \AA, c=$ 23.3841(17) ̊. $\alpha=90^{\circ}, \beta=90^{\circ}, \gamma=90^{\circ} . V=9905.7(12) \AA^{3}, Z=4$, $\rho$ calcd $=1.578 \mathrm{~cm}^{-3}, \mu=2.840 \mathrm{~mm}^{-1}, 56212$ measured reflections, 17421 independent reflections $\left(R_{\mathrm{int}}=0.0477\right), R_{1}=$ $0.0717[I>2 \sigma(I)], \mathrm{w} R_{2}=0.2124$ (all data), flack parameter: $0.05(3)$, goodness-of-fit on $F^{2}: 1.069$. Crystallographic data of $2 \mathbf{b}$ : $\mathrm{C}_{74} \mathrm{H}_{128} \mathrm{Cu}_{12} \mathrm{~N}_{6} \mathrm{O}_{8} \mathrm{~S}_{13}$, orthorhombic, $P 2_{1} 2_{1} 2_{1}, a=19.1023(9) \AA$, $b=23.8001(11) \AA$ А $c=24.5421(12) \AA . \alpha=90^{\circ}, \beta=90^{\circ}, \gamma=90^{\circ} . V$ $=11$ 157.7(9) $\AA^{3}, Z=4, \rho$ calcd $=1.434 \mathrm{~cm}^{-3}, \mu=2.523 \mathrm{~mm}^{-1}$, 125549 measured reflections, 19663 independent reflections $\left(R_{\text {int }}=0.0374\right), R_{1}=0.0490[I>2 \sigma(I)], \mathrm{w} R_{2}=0.1406$ (all data), flack parameter: $-0.004(4)$, goodness-of-fit on $F^{2}$ : 1.043. Crystallographic data of 3d: $\mathrm{C}_{85} \mathrm{H}_{102} \mathrm{Cl}_{0.7} \mathrm{Cu}_{12.3} \mathrm{~F}_{30} \mathrm{~N}_{6} \mathrm{OPS}_{12}$, orthorhombic, Pnna, $a=21.8103(5) \AA, b=22.9770(6) \AA, c=$ 22.0395(6) ̊. $\alpha=90^{\circ}, \beta=90^{\circ}, \gamma=90^{\circ} . V=11044.8(5) \AA^{3}, Z=4$, $\rho$ calcd $=1.814 \mathrm{~cm}^{-3}, \mu=2.670 \mathrm{~mm}^{-1}, 90620$ measured reflections, 9730 independent reflections $\left(R_{\mathrm{int}}=0.0303\right), R_{1}=$ $0.0450[I>2 \sigma(I)], \mathrm{w} R_{2}=0.1122$ (all data), goodness-of-fit on $F^{2}$ : 1.099. Crystallographic data of $3 \mathrm{e}: \mathrm{C}_{175} \mathrm{H}_{262} \mathrm{Cl}_{2} \mathrm{Cu}_{24} \mathrm{~F}_{12} \mathrm{~N}_{12} \mathrm{OP}_{2}$ -

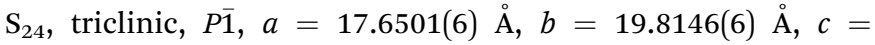
32.8484(11) Å. $\alpha=86.5157(9)^{\circ}, \beta=89.7691(9)^{\circ}, \gamma=75.7750(8)^{\circ}$. $V=11114.5(6) \AA^{3}, Z=2, \rho$ calcd $=1.555 \mathrm{~cm}^{-3}, \mu=2.561 \mathrm{~mm}^{-1}$, 83631 measured reflections, 39024 independent reflections $\left(R_{\text {int }}=0.0260\right), R_{1}=0.0664[I>2 \sigma(I)], \mathrm{w} R_{2}=0.1885$ (all data), goodness-of-fit on $F^{2}: 1.107$. Crystallographic data of $4 \mathrm{e}: \mathrm{C}_{86^{-}}$ $\mathrm{H}_{128} \mathrm{BrCu}_{12} \mathrm{~F}_{6} \mathrm{~N}_{6} \mathrm{PS}_{12}$, triclinic, $P \overline{1}, a=17.7551(15) \AA, \quad b=$

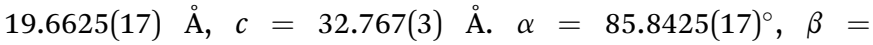
$85.6980(17)^{\circ}, \gamma=76.1094(16)^{\circ} . V=11055.9(16) \AA^{3}, Z=4, \rho$ calcd $=1.573 \mathrm{~cm}^{-3}, \mu=2.911 \mathrm{~mm}^{-1}, 63677$ measured reflections, 38372 independent reflections $\left(R_{\text {int }}=0.0533\right), R_{1}=$ 
$0.0806[I>2 \sigma(I)], \mathrm{w} R_{2}=0.2652$ (all data), goodness-of-fit on $F^{2}$ : 1.047. Crystallographic data of 5a: $\mathrm{C}_{132} \mathrm{H}_{234} \mathrm{Cl}_{5} \mathrm{Cu}_{24} \mathrm{~F}_{6} \mathrm{~N}_{12} \mathrm{O}_{12}$ -

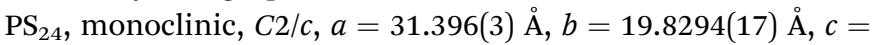
33.181(3) ̊. $\alpha=90^{\circ}, \beta=97.8261(17)^{\circ}, \gamma=90^{\circ} . \mathrm{V}=20465(3) \AA^{3}$, $Z=4, \rho$ calcd $=1.557 \mathrm{~cm}^{-3}, \mu=2.804 \mathrm{~mm}^{-1}, 56963$ measured reflections, 17945 independent reflections $\left(R_{\mathrm{int}}=0.0445\right), R_{1}=$ $0.0997[I>2 \sigma(I)], \mathrm{w} R_{2}=0.2334$ (all data), goodness-of-fit on $F^{2}$ : 1.015 .

\section{Computational details}

Geometry optimizations were performed using DFT calculations with the Gaussian 09 package ${ }^{24}$ using the PBE0 functional $^{25}$ and the all-electron Def2-TZVPP set from EMSL Basis Set Exchange Library. ${ }^{26}$ All the optimized geometries were characterized as true minima on their potential energy surface by harmonic vibrational analysis. The Wiberg bond indices were computed with the NBO 5.0 program. ${ }^{27}$ The UV-visible transitions were calculated by means of TD-DFT calculations, ${ }^{28}$ at the PBE0/Def2-TZVP level. Only singlet-singlet, i.e. spin-allowed, transitions were computed. The UV-visible spectra were simulated from the computed TD-DFT transitions and their oscillator strengths by using the SWizard program, ${ }^{29}$ each transition being associated with a Gaussian function of half-height width equal to $1500 \mathrm{~cm}^{-1}$. The compositions of the molecular orbitals were calculated using the AOMix program. ${ }^{30}$

\section{Conflicts of interest}

There are no conflicts to declare.

\section{Acknowledgements}

This work was supported by the Ministry of Science and Technology in Taiwan (MOST 106-2113-M-259-010). The GENCICINES and GENCI-IDRISS French national computer centres are acknowledged for computational resources (grant x2016087367).

\section{Notes and references}

1 (a) I. Haiduc, Coord. Chem. Rev., 2017, 338, 1-26; (b) I. Haiduc, Coord. Chem. Rev., 2017, 348, 71-91.

2 (a) C. W. Liu, H.-W. Chang, C.-S. Fang, B. Sarkar and J.-C. Wang, Chem. Commun., 2010, 46, 4571-4573; (b) C. Latouche, S. Kahlal, E. Furet, P.-K. Liao, Y.-R. Lin, C.-S. Fang, J. Cuny, C. W. Liu and J.-Y. Saillard, Inorg. Chem., 2013, 52, 7752-7765.

3 (a) R. S. Dhayal, J.-H. Liao, Y.-R. Lin, P.-K. Liao, S. Kahlal, J.-Y. Saillard and C. W. Liu, J. Am. Chem. Soc., 2013, 135, 4704-4707; (b) C. W. Liu, B. Sarkar, Y.-J. Huang, P.-K. Liao, J.-C. Wang, J.-Y. Saillard and S. Kahlal, J. Am. Chem. Soc., 2009, 131, 11222-11233; (c) T. S. Lobana, J.-C. Wang and C. W. Liu, Coord. Chem. Rev., 2007, 251, 91-110.

4 (a) J.-H. Liao, C. Latouche, B. Li, S. Kahlal, J.-Y. Saillard and C. W. Liu, Inorg. Chem., 2014, 53, 2260-2267; (b) Y. B. Chen,
Z. J. Li, Y. Y. Qin, Y. Kang, J. K. Cheng, R. F. Hu, Y. H. Wen and Y. G. Yao, Inorg. Chem. Commun., 2003, 6, 405; (c) C. W. Liu, C. M. Hung, B. K. Santra, H. C. Chen, H. H. Hsueh and J. C. Wang, Inorg. Chem., 2003, 42, 32163220; (d) C. W. Liu, M. D. Irwin, A. A. Mohamed and J. P. Fackler Jr, Inorg. Chim. Acta, 2004, 357, 3950-3956; (e) C. W. Liu, C. M. Hung, H. C. Haia, B. J. Liaw, L. S. Liou, Y. F. Tsai and J. C. Wang, Chem. Commun., 2003, 976-977; (f) C. W. Liu, H. C. Haia, C. M. Hung, B. K. Santra, B. J. Liaw, Z. Y. Lin and J. C. Wang, Inorg. Chem., 2004, 43, 4464-4470; $(g)$ C. W. Liu, Phosphorus, Sulfur Silicon Relat. Elem., 2005, 180, 923; (h) Z.-H. Wei, C.-Y. Ni, H.-X. Li, Z.-G. Ren, Z.-R. Sun and J.-P. Lang, Chem. Commun., 2013, 49, 4836-4838; (i) Y.-J. Li, C. Latouche, S. Kahlal, J.-H. Liao, R. S. Dhayal, J.-Y. Saillard and C. W. Liu, Inorg. Chem., 2012, 51, 7439-7441.

5 (a) B. Li, J.-H. Liao, H.-T. Tang, Y.-J. Li and C. W. Liu, Dalton Trans., 2013, 42, 14384-14387; (b) C. Latouche, J.-H. Liao, Y.-J. Li, R.-Y. Shiu, V. Barone, S. Kahlal, C. W. Liu and J.-Y. Saillard, Inorg. Chem., 2017, 56, 14135-14146; (c) C. W. Liu, C.-M. Hung, B. K. Santra, Y.-H. Chu, J.-C. Wang and Z. Lin, Inorg. Chem., 2004, 43, 4306-4314.

6 F. Scherbaum, A. Grohmann, B. Huber, C. Krgger and H. Schmidbaur, Angew. Chem., Int. Ed. Engl., 1988, 27, 1544-1546.

7 (a) Y.-Q. Hu, M.-H. Zeng, K. Zhang, S. Hu, F.-F. Zhou and M. Kurmoo, J. Am. Chem. Soc., 2013, 135, 7901-7908; (b) X. Yang and M. B. Hall, J. Am. Chem. Soc., 2007, 129, 15601567.

8 (a) S. J. Hilsenbeck, V. G. Young Jr and R. E. McCarley, Inorg. Chem., 1994, 33, 1822-1832; (b) X. Zhang and R. E. McCarley, Inorg. Chem., 1995, 34, 2678-2683.

9 (a) R. P. B. Silalahi, K. K. Chakrahari, J.-H. Liao, S. Kahlal, Y.-C. Liu, M.-H. Chiang, J.-Y. Saillard and C. W. Liu, Chem.-Asian J., 2018, 13, 500-504; (b) K. K. Chakrahari, J.-H. Liao, S. Kahlal, Y.-C. Liu, M.-H. Chiang, J.-Y. Saillard and C. W. Liu, Angew. Chem., Int. Ed., 2016, 55, 14704-14708. 10 (a) W. A. de Heer, Rev. Mod. Phys., 1993, 65, 611-675; (b) S. N. Khanna and P. Jena, Phys. Rev. B: Condens. Matter Mater. Phys., 1995, 51, 13705-13716; (c) M. Walter, J. Akola, O. Lopez-Acevedo, P. D. Jadzinsky, G. Alero, C. J. Ackerson, R. L. Whetten, H. Gronbeck and H. A. Hakkinen, Proc. Natl. Acad. Sci. U. S. A., 2008, 105, 9157-9162.

11 T.-A. D. Nguyen, Z. R. Jones, B. R. Goldsmith, W. R. Buratto, G. Wu, S. L. Scott and T. W. Hayton, J. Am. Chem. Soc., 2015, 137, 13319-13324.

12 T.-A. D. Nguyen, Z. R. Jones, D. F. Leto, G. Wu, S. L. Scott and T. W. Hayton, Chem. Mater., 2016, 28, 8385-8390.

13 A. W. Cook, Z. R. Jones, G. Wu, S. L. Scott and T. W. Hayton, J. Am. Chem. Soc., 2018, 140, 394-400.

14 H.-Y. Chao, L. Wu, B.-C. Su and X.-L. Feng, Inorg. Chem. Commun., 2011, 14, 122-124.

15 G. Hogarth, Prog. Inorg. Chem., 2005, 53, 71.

16 (a) R. S. Dhayal, J.-H. Liao, Y.-C. Liu, M.-H. Chiang, S. Kahlal, J.-Y. Saillard and C. W. Liu, Angew. Chem., Int. Ed., 2015, 54, 3702-3706; (b) R. S. Dhayal, Y.-R. Lin, J.-H. Liao, Y.-J. Chen, Y.-C. Liu, M.-H. Chiang, S. Kahlal, J.-Y. Saillard and 
C. W. Liu, Chem.-Eur. J., 2016, 22, 9943-9947; (c) W.-T. Chang, P.-Y. Lee, J.-H. Liao, K. K. Chakrahari, S. Kahlal, Y.-C. Liu, M.-H. Chiang, J.-Y. Saillard and C. W. Liu, Angew. Chem., Int. Ed., 2017, 56, 10178-10182; (d) Y.-R. Lin, P. V. V. N. Kishore, J.-H. Liao, S. Kahlal, Y.-C. Liu, M.-H. Chiang, J.-Y. Saillard and C. W. Liu, Nanoscale, 2018, 10, 6855-6860.

17 (a) P. Betz, B. Krebs and G. Henkel, Angew. Chem., Int. Ed. Engl., 1984, 23, 311-312; (b) P. Reiß and D. Fenske, Z. Anorg. Allg. Chem., 2000, 626, 1317-1331; (c) N. Wiberg, A. Wörner, D. Fenske, H. Nöth, J. Knizek and K. Polborn, Angew. Chem., Int. Ed., 2000, 39, 1838-1842; (d) O. Fuhr, S. Dehnen and D. Fenske, Chem. Soc. Rev., 2013, 42, 18711906 and references cited therein.

18 (a) S.-P. Huang and M. G. Kanatzidis, Angew. Chem., Int. Ed. Engl., 1992, 31, 787-789; (b) V. G. Albano, L. Grossi, G. Longoni, M. Monari, S. Mulley and A. Sironi, J. Am. Chem. Soc., 1992, 114, 5708-5713.

19 P. V. V. N. Kishore, J.-H. Liao, H.-N. Hou, Y.-R. Lin and C. W. Liu, Inorg. Chem., 2016, 55, 3663-3673.

20 SAINT V4.043: Software for CCDC Detector System, Bruker Analystic X-ray Systems, Madison, WI, 1995.

21 G. M. Sheldrick, SADABS, University of Göttingen, Göttingen, Germany, 1996.

22 G. M. Sheldrick, Acta Crystallogr., 2015, C71, 3.

23 SHELXL v6.14 (PC version) Program Library for Structure Solution and Molecular Graphics, Bruker Analytical X-ray Systems, Madison, WI, 1998.

24 M. J. Frisch, G. W. Trucks, H. B. Schlegel, G. E. Scuseria, M. A. Robb, J. R. Cheeseman, G. Scalmani, V. Barone, B. Mennucci, G. A. Petersson, H. Nakatsuji, M. Caricato, X. Li, H. P. Hratchian, A. F. Izmaylov, J. Bloino, G. Zheng, J. L. Sonnenberg, M. Hada, M. Ehara, K. Toyota,
R. Fukuda, J. Hasegawa, M. Ishida, T. Nakajima, Y. Honda, O. Kitao, H. Nakai, T. Vreven, J. A. Montgomery Jr, J. E. Peralta, F. Ogliaro, M. Bearpark, J. J. Heyd, E. Brothers, K. N. Kudin, V. N. Staroverov, R. Kobayashi, J. Normand, K. Raghavachari, A. Rendell, J. C. Burant, S. S. Iyengar, J. Tomasi, M. Cossi, N. Rega, J. M. Millam, M. Klene, J. E. Knox, J. B. Cross, V. Bakken, C. Adamo, J. Jaramillo, R. Gomperts, R. E. Stratmann, O. Yazyev, A. J. Austin, R. Cammi, C. Pomelli, J. W. Ochterski, R. L. Martin, K. Morokuma, V. G. Zakrzewski, G. A. Voth, P. Salvador, J. J. Dannenberg, S. Dapprich, A. D. Daniels, O. Farkas, J. B. Foresman, J. V. Ortiz, J. Cioslowski and D. J. Fox, Gaussian 09, Revision E.01, Gaussian, Inc., Wallingford CT, 2009.

25 (a) J. P. Perdew, M. Ernzerhof and K. Burke, J. Chem. Phys., 1996, 105, 9982-9985; (b) J. P. Perdew, M. Burke and M. Ernzerhof, Phys. Rev. Lett., 1996, 77, 3865-3868; (c) J. P. Perdew, K. Burke and M. Ernzerhof, Phys. Rev. Lett., 1997, 78, 1396.

26 F. Weigend and R. Ahlrichs, Phys. Chem. Chem. Phys., 2005, 7, 3297-3305.

27 E. D. Glendening, J. K. Badenhoop, A. E. Reed, J. E. Carpenter, J. M. Bohmann, C. M. Morales and F. Weinhold, Theoretical Chemistry Institute, University of Wisconsin, Madison, WI, 2001, http://www.chem.wisc.edu/ $\sim$ nbo5.

28 K. Burke and E. K. U. Gross, A guided tour of TimeDependent Density Functional Theory, in Density Functionals: Theory and Applications, (Lecture Notes in physics), ed. D. Joubert, Springer, 1998, vol. 500.

29 S. I. Gorelsky, SWizard program, revision 4.5, http:/www.sgchem.net/.

30 S. I. Gorelsky, AOMix program, http:/www.sg-chem.net/. 